\title{
Efectos del coronavirus en el sistema de enseñanza: aumenta la desigualdad de oportunidades educativas en España
}

\author{
Effects of the Coronavirus in the Education System: \\ The Inequality of Educational Opportunities in Spain Increases
}

Leopoldo Cabrera'

\begin{abstract}
Resumen
La pandemia del Coronavirus ha cerrado los centros educativos en España desde mediados de marzo de 2020. No se prevé su apertura en este curso, salvo para exámenes en el Bachillerato y en la Universidad. La enseñanza online, con implantación diferencial por tipo de centros y regiones, sustituye en este período a la enseñanza presencial en los centros escolares.

Este modelo educativo telemático incrementa la desigualdad de oportunidades educativas. Pone de manifiesto las carencias materiales de dispositivos electrónicos en los hogares más desfavorecidos, en los hogares de menores rentas y recursos, más aún en los hogares monoparentales, más aún en los hogares con padres de estudios secundarios obligatorios o menos (padre y madre, o peor, solo uno de ellos), más aún en los alumnos de centros públicos y más aún en los estudiantes que viven en las comunidades del Sur, incluidas Galicia y Canarias.

Si bien todo el alumnado, y sus familias, está afectado negativamente por el cierre de los centros educativos, casi un millón de ellos (variable según las fuentes de registro usadas) lo está aún más por sus condiciones personales y familiares.

Este artículo muestra que la enseñanza telemática online actual, sin discutir sus bondades y apoyo para los procesos de aprendizaje, incrementa las desigualdades educativas del alumnado.
\end{abstract}

\section{Palabras clave}

Desigualdad social, desigualdad de oportunidades educativas, recursos electrónicos del hogar, tipología de familias, enseñanza pública y enseñanza privada, Comunidades Autónomas.

\begin{abstract}
The Coronavirus pandemic has closed schools in Spain since mid-March 2020. It is not expected to open this year, except for examinations in upper secondary and at the University. Online teaching, with differential implementation by type of center and region, replaces in this period face-to-face teaching in schools.

This telematic educational model increases the inequality of educational opportunities. It highlights the material shortages of electronic devices in the most disadvantaged households, in the households with the lowest incomes and resources, even more so in single-parent households, even more in households with parents of compulsory secondary education or less (father and mother, or worse, only one of them), even more so in public school students and even more so in students living in the Southern Communities, including Galicia and the Canary Islands.

Although all the students, and their families, are negatively affected by the closure of the educational centers, almost a million of them (variable according to the registration sources used) are even more affected by their personal and family conditions.

This article shows that current online telematic education, without discussing its benefits and support for learning processes, increases the educational inequalities of students.
\end{abstract}

\section{Keywords}

Social inequality, inequality of educational opportunities, electronic resources at home, typology of families, public/private education, regions.

\section{Cómo citar/Citation}

Cabrera, Leopoldo (2020). Efectos del coronavirus en el sistema de enseñanza: aumenta la desigualdad de oportunidades educativas en España. Revista de Sociología de la Educación-RASE, 13 (2) Especial, COVID-19, 114-139. http://dx.doi.org/10.7203/RASE.13.2.17125.

\footnotetext{
1 Leopoldo Cabrera, Departamento de Sociología y Antropología Universidad de La Laguna, lcabre@ull.edu.es.
} 


\section{Introducción}

Una situación excepcional se vive en España desde marzo de 2020 por efecto del Coronavirus (COVID-19). La pandemia ha forzado el cierre de los centros educativos, tanto universitarios como no universitarios. Las clases presenciales se han suprimido. Asistimos a un escenario imprevisible que despierta y suscita inquietud por sus efectos sociales, económicos, personales y familiares.

En el sistema educativo los problemas son múltiples. Un final de curso nuevo, controvertido, con evaluaciones no programadas (posiblemente virtuales), con aulas en red, cuando ha sido y es posible, páginas webs de los centros saturadas, docentes y alumnos enfrentados a un aprendizaje con recursos en línea no siempre suficientes. Las aulas virtuales han sustituido a las aulas físicas de los centros, previsiblemente durante casi un trimestre. La incertidumbre y los cambios que se avecinan se adueñan del profesorado, alumnado y familias. Suponen una novedad manifiesta que altera sustancialmente la vida escolar cotidiana.

Múltiples cuestiones son objeto de debate en la situación actual. ¿Qué será del actual sistema de enseñanza? ¿Qué consecuencias deparará para los estudiantes el cierre escolar? ¿Se agrandará la desigualdad de oportunidades? ¿Aumentará la competitividad? ¿Cambiarán las relaciones personales y sociales? ¿La virtualidad se extenderá en el futuro o convivirá con nosotros de forma permanente? ¿A todo el alumnado le afecta por igual, o el de Primaria lo tiene peor? ¿Las clases prácticas de laboratorio del alumnado de Bachillerato se recuperarán? ¿Las prácticas de laboratorio y profesionales del alumnado de enseñanza profesional (ciclos formativos de grados medio y superior de Formación Profesional) se recuperarán? ¿Cómo quedan afectados los procesos de enseñanza aprendizaje a través del juego entre niños? ¿Las relaciones personales en las aulas pueden ser virtuales? Los efectos trascienden, en cualquier caso, al sistema educativo formal.

Estas preguntas y otras muchas rondan a gran parte de la población, familias, estudiantes, docentes y, particularmente, a investigadores e investigadoras en educación y sociedad. Es el caso de los sociólogos de la educación de la Europa del Sur que tenían prevista una reunión en Milán el próximo 25 y 26 de mayo (https://aps.pt/pt/sociology-of-education-in-southern-europe/), pospuesta por el coronavirus al próximo año 2021 en similares fechas (24, 25 y 26 de mayo), pendiente de ratificación en la próxima reunión (la séptima) por videoconferencia en septiembre de este año ${ }^{2}$. La actualidad del coronavirus y sus consecuencias en el sistema educativo han sido objeto de debate en la sexta reunión del Comité Organizador de Milán 2020, celebrada por videoconferencia el pasado 24 de marzo. El Comité Organizador acordó realizar un llamamiento especial de comunicaciones específicas sobre las incidencias del coronavirus en los sistemas educativos de los países del Sur de Europa en septiembre de este año, con más tiempo y sosiego para la reflexión e investigación.

Entretanto, podemos generar afirmaciones y conjeturas de sus efectos y afecciones, especialmente sobre la desigualdad de oportunidades educativas. Este artículo se centra en este análisis. En algunos casos con suposiciones sobre lo qué está ocurriendo con los jóvenes en sus contextos familiares de confina-

2 Esta iniciativa se remonta a una primera reunión en Lisboa en julio de 2015 de los Comités-Asociaciones de Sociología de la Educación de Portugal y España y a una segunda en Córdoba en julio de 2017. En esta última se invitó a varios miembros de la Asociación Italiana de Sociología de la Educación y surgen los primeros contactos para celebrar una reunión conjunta en Milán en mayo de 2020. Una reunión posterior en junio de 2019 en Cagliari (Cerdeña) en el marco de la Conferencia Scuola Democratica (First International Conference: Education and Post-Democracy), con más de 500 participantes, miembros de la Asociación Portuguesa de Sociología de la Educación, del Comité Español de Sociología de la Educación, de la Asociación Italiana de Sociología de la Educación y ahora de la Asociación Francesa de Sociología de la Educación, dedican una sesión especial: Session C 01 a [Special session] Geo-Politics of Educational Policies and Neoliberal Worldwide Hegemony: Convenor(s), dirigida por Filippo Pirone (Université de Bordeaux), Marco Pitzalis (University of Cagliari), Leopoldo Cabrera (Universidad de La Laguna) y Leonor Lima (Universidade do Minho), (http://www.scuolademocratica-conference.net/wp-content/uploads/2019/05/GENERAL-BOOKLET-DEF-finale-con-aule-2.pdf), como avance de la Conferencia de Milán de 2020, que se ratifica en la sesión de la Asociación Italiana celebrada en Cagliari en esas fechas. 
miento y sus repercusiones en el aprendizaje. Básicamente circunscritos a tipología de hogares y recursos que unos y otros estudiantes disponen para aceptar y seguir una enseñanza virtual a distancia, cuando el profesorado tiene también disponibilidad de hacerla efectiva. Partimos de que la composición familiar, los niveles educativos de sus padres (o madre, o padre), sus rentas, el número de hijos en el hogar, la propia tipología de las familias, etc., afectarán negativamente a todo el alumnado, más aún al grupo de alumnos de hogares desfavorecidos y al escolarizado en centros públicos. La casuística es tal que no es sencillo determinar cómo, dónde y a quién afecta más este cierre escolar y este cambio de enseñanza presencial a enseñanza virtual. Sin embargo, creemos poder mostrar que si bien todo el alumnado, y sus familias, está afectado negativamente por el cierre de los centros educativos, casi un millón o más (depende de la fuente) lo está aún más por sus condiciones personales y familiares.

Este artículo muestra que la enseñanza telemática online actual, sin discutir sus bondades y apoyo en los procesos de aprendizaje, incrementa las desigualdades educativas existentes del alumnado en los centros educativos de enseñanza presencial.

Comenzamos el análisis con las cifras de la educación en España que contabiliza el alumnado afectado directamente por el cierre escolar. Seguidamente describimos la tipología de los hogares por los recursos que poseen, prestando atención especial a la tenencia o no de dispositivos electrónicos y a la conexión a internet. Posteriormente, mostramos que el alumnado afectado no se distribuye aleatoriamente ni por hogares y familias (formación, renta y recursos), ni por regiones, ni por tipología de centros (públicos/ privados); para, recapitulando, concluir que el efecto final del cierre escolar, negativo para todo el alumnado y sus familias, lo es más para el alumnado de familias más desfavorecidas, de centros públicos y del Sur (incluyendo a Galicia y Canarias), aumentando, en síntesis, la desigualdad de oportunidades educativas.

\section{Las cifras de la educación en España: niveles educativos y titularidad de centros}

El cierre de los centros escolares universitarios y no universitarios afecta directamente a casi una de cada cuatro personas que viven en España $(25,02 \%)^{3}$ y a la mitad de los hogares existentes donde habita al menos un joven menor de edad ${ }^{4}$.

Se trata, por la parte del alumnado, de algo más de 8,2 millones de escolares en la enseñanza no universitaria (1,7 millones en Infantil, 3 millones en Primaria, alrededor de 2 millones en Secundaria Obligatoria, 0,67 millones en Bachillerato, 0,86 en Enseñanza Profesional), 1,6 millones en la Universitaria, 0,8 millones en enseñanzas artísticas, deportivas y de idiomas y 0,2 en educación de adultos (MEyFP, 2020: Indicador C1.1).

Dos de cada tres alumnos de los 8,2 millones matriculados en la enseñanza no universitaria lo están en centros públicos (alrededor de 5,5 millones), aunque no repartidos de igual forma por la geografía nacional, como se recoge en el gráfico 1 que sigue y en el gráfico 1 del anexo que ofrece la distribución de participación pública en alumnado matriculado por niveles educativos.

\footnotetext{
Los datos definitivos detallados de educación del curso 2017-18 publicados en febrero de 2020 por el MEyFP (Las cifras de la educación en España), registraban 10814764 alumnos matriculados (Indicador C1.1) frente a una población total en España de 46722980 personas (Indicador A1.1), con una proporción de alumnado del 23,15\% respecto a la población total. Si a ello le sumamos, 701385 profesores en la enseñanza no universitaria y 122910 en la universitaria y 50703 en enseñanzas artísticas, deportivas, de idiomas y de adultos (874998 profesores en total), nos encontramos con 11689762 alumnos y profesores que representan un $25,02 \%$ de la población española.

4 Según datos de Hogares en la Encuesta de Condiciones de Vida 2018 (ECV) del INE y de la Encuesta sobre Equipamiento y Uso de Tecnologias de Información y Comunicación en Hogares 2019 del INE.
} 


\section{Gráfico 1. Alumnado matriculado en la enseñanza no universitaria por Comunidades Autónomas y Titularidad de Centros. Curso 2017-18}

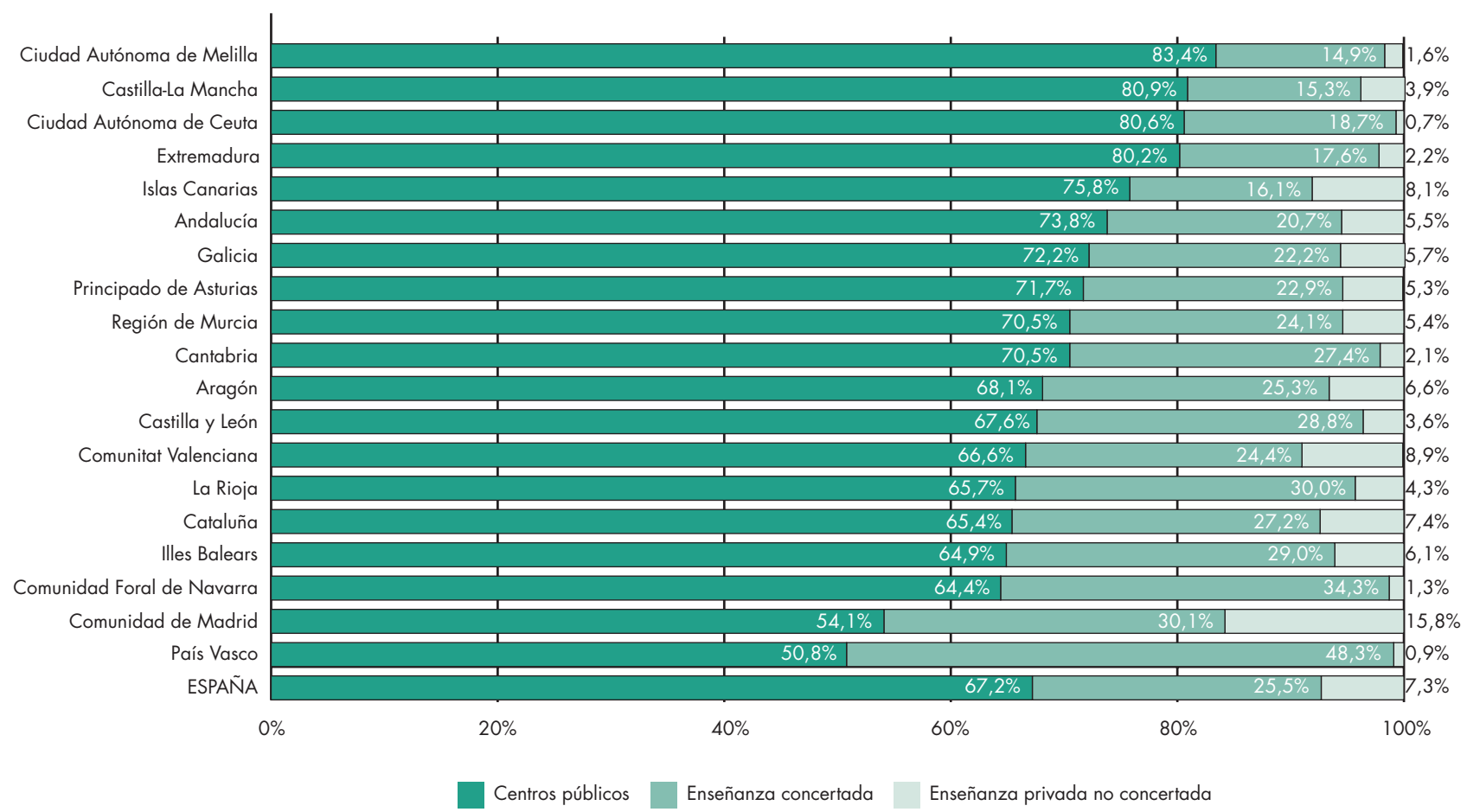

Fuente: MEyFP (2019: 19). Datos y Cifras. Curso Escolar 2019-2020.

Esta información es relevante por la asociación estrecha existente entre la proporción de alumnado escolarizado en centros públicos en las distintas comunidades autónomas y sus niveles de renta, con una imagen estructural de desigualdad regional incrementada con el paso de los años (Cabrera, 2013). Esta distribución territorial de la desigualdad de educación y renta (asociada a los niveles educativos alcanzados por la población) afecta al equipamiento de los hogares (como veremos). Está asociada asimismo a la desigual presencia de alumnado matriculado en centros escolares privados, que, por otra parte, han introducido y gestionado el apoyo de la enseñanza presencial con soporte virtual desde hace más tiempo y generalizado su uso en su alumnado que cuenta con más soporte de equipamiento de ordenadores y tabletas, conexión a internet de banda ancha y apoyo familiar de capital cultural-humano (padres con más niveles de formación) para ello.

Veamos ahora la tipología y características de los hogares donde viven los jóvenes escolares, el grueso del sistema educativo.

\section{Los hogares en España: composición, tamaño y carencia de material (dispositivos electrónicos y conexión a internet).}

Los datos proporcionados por el INE (2020, Encuesta Continua de Hogares, ECH) registran 18625700 de hogares en España con una media de 2,5 personas por hogar. Un tercio de estos hogares está formado por parejas que viven con uno o más hijos $(33,4 \%)$ y uno de cada diez hogares está formado por un solo progenitor (padre o madre) con uno o más hijos. La descomposición de hogares por tipo de hogar y número de habitaciones registra un 3\% de los hogares donde viven parejas con 3 o más hijos (un 2\% de estos hogares tienen menos de 3 habitaciones), un 15\% de hogares por parejas y dos hijos y un 16\% 
de hogares compuestos por una pareja con un único hijo, un 10\% de hogares donde son monoparentales con hijos, dando un porcentaje del $43 \%$ de hogares en España con niños, casi en su totalidad en hogares con 3 habitaciones o más (ver tabla I del anexo).

La Encuesta de Condiciones de Vida (ECV) de 2018 del INE muestra el descenso anual paulatino en la proporción de hogares con carencia de material que no pueden permitirse disponer de un ordenador en su casa (ver tabla II del anexo). Son un 5,5\% de hogares en 2018, la mitad que había en 2006, si bien parece que esta proporción se ha estabilizado en los últimos años. La carencia de ordenador en los hogares es mayor en los grupos de menor edad (ver tabla II del anexo) y se duplica en los hogares monoparentales con un padre o madre con uno o más hijos, manteniéndose esta tendencia en el tiempo (ver tabla III del anexo).

Por deciles de renta, la ECV de 2018 muestra que la carencia de ordenador personal afecta a más proporción de personas cuando menor es su decil de renta: 22,3\% decil 1; 10,4\% decil 2; 6,4\% decil 3; $6,1 \%$ decil 4; 3,9\% decil 5; 2,2\% decil 6; $1,9 \%$ decil 7; 1,1\% decil 8; $1,0 \%$ decil 9 y $0,2 \%$ decil 10 . Otro tanto ocurre por niveles de estudios: cuantos menos estudios se tienen, más proporción de carencia de ordenadores $(8,4 \%$ con estudios primarios o menos; $7,1 \%$ con secundarios de primera etapa; $4,5 \%$ con secundarios de segunda etapa y $1,2 \%$ con estudios superiores).

Datos muy cercanos en el tiempo procedentes de La Encuesta de Equipamiento y Uso de Tecnologías de Información y Comunicación en Hogares del INE de 2019 (publicados en octubre) arrojan registros menos alentadores que la ECV de 2018 cuando se refieren a hogares con al menos una persona de 16 a 74 años. Muestran (ver tabla I que sigue y tabla $\mathrm{V}$ del anexo) que un 80,9\% de los hogares disponen de algún tipo de ordenador (en oposición, un 19,1\% no dispone); proporción que sube al 93,1\% en los hogares con pareja e hijos y al 82,0\% en los hogares monoparentales con al menos un hijo (casi un 10\% menos que se refleja en España y en casi todas las Comunidades Autónomas, ver tabla II que sigue). Ofrecen asimismo información relativa al uso de internet ( $91,4 \%$ de los hogares disponen de acceso, ver tabla VI del anexo), que alcanza al 97,8\% en los hogares de parejas con hijos por un 92,6\% en hogares monoparentales con algún hijo. Por ingresos mensuales del hogar se observa que casi la totalidad de los hogares con ingresos mensuales netos por encima de 2500 euros dispone de ordenador y conexión a internet, frente al 58,1\% de los hogares con ingresos inferiores a 900 euros o al 76,7\% de los hogares con ingresos mensuales netos comprendidos entre 900 euros y 1600 euros que disponen de ordenador y 77,9\% y 90,5\% que disponen de conexión a internet, respectivamente. Por hábitat, los municipios con más habitantes suben ligeramente la proporción del 80,9\% general de tenencia de ordenadores y elevan ligeramente del 91,4\% al 93,5\% la conexión a internet (tabla I que sigue). Y, finalmente y a grandes rasgos, las Comunidades del Norte (Navarra, País Vasco, Aragón, Madrid y Cataluña) cuentan con más proporción de ordenadores (ver tabla II), más conexión a internet (ver tabla II), con banda ancha y teléfono fijo, mientras la tenencia de móvil es habitual en prácticamente todas las viviendas (98,5\%) como se ve en la tabla I que sigue y en la tabla IV del anexo, si bien es menor en el grupo de jóvenes de 10 a 15 años (tabla VII del anexo). 


\section{Tabla I. Viviendas por tamaño del hogar, hábitat, tipo de hogar, ingresos} mensuales netos del hogar y tipo de equipamiento

\begin{tabular}{|c|c|c|c|c|c|c|}
\hline & $\begin{array}{c}\text { TOTAL } \\
\text { VIVIENDAS }\end{array}$ & $\begin{array}{l}\text { VIVIENDAS CON } \\
\text { ALGÚN TIPO DE } \\
\text { ORDENADOR }\end{array}$ & $\begin{array}{l}\text { VIVIENDAS } \\
\text { QUE DISPONEN } \\
\text { DE ACCESO A } \\
\text { INTERNET }\end{array}$ & $\begin{array}{l}\text { VIVIENDAS CON } \\
\text { CONEXIÓN DE } \\
\text { BANDA ANCHA } \\
\text { (ADSL, RED DE } \\
\text { CABLE, ETC) }\end{array}$ & $\begin{array}{l}\text { VIVIENDAS CON } \\
\text { TELÉFONO FIJO }\end{array}$ & $\begin{array}{l}\text { VIVIENDASCON } \\
\text { TELÉFONO MÓVIL }\end{array}$ \\
\hline Total viviendas & 16451384 & 80,9 & 91,4 & 91,2 & 74,9 & 98,5 \\
\hline $\begin{array}{l}\text { Tipo de hogar: } \\
\text { Hogar unipersonal }\end{array}$ & 3332378 & 67,7 & 84,8 & 84,5 & 60,5 & 96,8 \\
\hline $\begin{array}{l}\text { Tipo de hogar: padre o madre solo/a } \\
\text { que conviva con algún hijo }\end{array}$ & 1909021 & 82,0 & 92,6 & 92,2 & 78,2 & 98,0 \\
\hline $\begin{array}{l}\text { Tipo de hogar: pareja sin hijos que } \\
\text { convivan en el hogar }\end{array}$ & 3132154 & 70,0 & 84,8 & 84,4 & 74,4 & 97,8 \\
\hline $\begin{array}{l}\text { Tipo de hogar: pareja con hijos que } \\
\text { convivan en el hogar }\end{array}$ & 6498914 & 93,1 & 97,8 & 97,6 & 80,8 & 99,8 \\
\hline $\begin{array}{l}\text { Tipo de hogar: } \\
\text { Otro tipo de hogar }\end{array}$ & 1578917 & 79,1 & 91,0 & 90,8 & 78,0 & 98,3 \\
\hline $\begin{array}{l}\text { Hábitat: de } 100000 \text { y más } \\
\text { habitantes y capitales de provincia }\end{array}$ & 7027307 & 84,8 & 93,5 & 93,4 & 82,2 & 98,9 \\
\hline $\begin{array}{l}\text { Hábitat: de } 50000 \text { a menos de } \\
100000 \text { habitantes }\end{array}$ & 1963552 & 81,5 & 92,1 & 92,0 & 75,4 & 98,6 \\
\hline $\begin{array}{l}\text { Hábitat: de } 20000 \text { a menos de } \\
50000 \text { habitantes }\end{array}$ & 2446418 & 79,7 & 91,7 & 91,6 & 70,7 & 98,4 \\
\hline $\begin{array}{l}\text { Hábitat: de } 10000 \text { a menos de } \\
20000 \text { habitantes }\end{array}$ & 1795397 & 78,7 & 90,8 & 90,8 & 68,7 & 98,0 \\
\hline $\begin{array}{l}\text { Hábitat: } \\
\text { Menos de } 10000 \text { habitantes }\end{array}$ & 3218710 & 74,1 & 86,8 & 85,6 & 65,2 & 97,8 \\
\hline $\begin{array}{l}\text { Ingresos mensuales netos del hogar: } \\
\text { Menos de } 900 \text { euros }\end{array}$ & 2695328 & 58,1 & 77,9 & 77,4 & 57,9 & 95,5 \\
\hline $\begin{array}{l}\text { Ingresos mensuales netos del hogar: } \\
900 \text { a menos de } 1600 \text { euros }\end{array}$ & 4952780 & 76,7 & 90,5 & 90,2 & 70,1 & 98,4 \\
\hline $\begin{array}{l}\text { Ingresos mensuales netos hogar: } \\
1600 \text { a menos de } 2500 \text { euros }\end{array}$ & 3267361 & 91,9 & 97,4 & 97,2 & 81,5 & 99,7 \\
\hline $\begin{array}{l}\text { Ingresos mensuales netos del hogar: } \\
2500 \text { o más euros }\end{array}$ & 2765923 & 97,4 & 99,2 & 99,1 & 89,0 & 99,9 \\
\hline $\begin{array}{l}\text { Ingresos mensuales netos del hogar: } \\
\text { NS/NR }\end{array}$ & 2769991 & 81,4 & 91,5 & 91,3 & 78,0 & 98,4 \\
\hline
\end{tabular}

Unidades: $\mathrm{n}^{\circ}$ de viviendas (con al menos un miembro de 16 a 74 años) y \% horizontales.

Fuente: INE (2019). Encuesta sobre Equipamiento y Uso de Tecnologías de Información y Comunicación en Hogares (TIC-H’19).

Tabla II. Viviendas totales por Comunidades Autónomas por hogares con niños monoparentales o con pareja que tienen algún tipo de ordenador (\%) y conexión a internet (\%)

\begin{tabular}{|c|c|c|c|}
\hline & $\begin{array}{c}\text { TOTAL } \\
\text { VIVIENDAS }\end{array}$ & $\begin{array}{l}\text { VIVIENDAS CON ALGÚN } \\
\text { TIPO DE ORDENADOR }\end{array}$ & $\begin{array}{c}\text { VIVIENDAS } \\
\text { QUE DISPONEN DE ACCESO } \\
\text { A INTERNET }\end{array}$ \\
\hline Total viviendas ESPAÑA & 16451384 & 80,9 & 91,4 \\
\hline Tipo de hogar: Padre o madre solo/a que conviva con algún hijo & 1909021 & 82,0 & 92,6 \\
\hline Tipo de hogar: Pareja con hijos que convivan en el hogar & 6498914 & 93,1 & 97,8 \\
\hline Total viviendas ANDALUCíA & 2874364 & 76,8 & 98,7 \\
\hline Tipo de hogar: Padre o madre solo/a que conviva con algún hijo & 327755 & 74,8 & 90,3 \\
\hline Tipo de hogar: Pareja con hijos que convivan en el hogar & 1235393 & 92,3 & 97,6 \\
\hline
\end{tabular}




\begin{tabular}{|c|c|c|c|}
\hline & $\begin{array}{c}\text { TOTAL } \\
\text { VIVIENDAS }\end{array}$ & $\begin{array}{l}\text { VIVIENDAS CON ALGÚN } \\
\text { TIPO DE ORDENADOR }\end{array}$ & $\begin{array}{c}\text { VIVIENDAS } \\
\text { QUE DISPONEN DE ACCESO } \\
\text { A INTERNET }\end{array}$ \\
\hline Total viviendas ARAGÓN & 471109 & 84,9 & 92,1 \\
\hline Tipo de hogar: Padre o madre solo/a que conviva con algún hiijo & 48284 & 90,0 & 93,8 \\
\hline Tipo de hogar: Pareja con hijos que convivan en el hogar & 176972 & 95,5 & 98,2 \\
\hline Total viviendas PRINCIPADO DE ASTURIAS & 394125 & 79,5 & 91,1 \\
\hline Tipo de hogar: Padre o madre solo/a que conviva con algún hiio & 39644 & 74,4 & 86,3 \\
\hline Tipo de hogar: Pareja con hijos que convivan en el hogar & 125031 & 96,0 & 99,0 \\
\hline Total viviendas ILLES BALEARS & 414736 & 84,5 & 93,1 \\
\hline Tipo de hogar: Padre o madre solo/a que conviva con algún hijo & 54840 & 91,2 & 98,4 \\
\hline Tipo de hogar: Pareja con hijos que convivan en el hogar & 160767 & 91,9 & 97,8 \\
\hline Total viviendas ISLAS CANARIAS & 781388 & 80,3 & 91,1 \\
\hline Tipo de hogar: Padre o madre solo/a que conviva con algún hiio & 103017 & 77,0 & 89,3 \\
\hline Tipo de hogar: Pareja con hijos que convivan en el hogar & 286770 & 94,1 & 98,6 \\
\hline Total viviendas CANTABRIA & 209549 & 80,7 & 90,8 \\
\hline Tipo de hogar: Padre o madre solo/a que conviva con algún hiijo & 26218 & 81,6 & 90,4 \\
\hline Tipo de hogar: Pareja con hijos que convivan en el hogar & 73251 & 90,7 & 94,7 \\
\hline Total viviendas CASTILLA Y LEÓN & 846519 & 78,0 & 89,0 \\
\hline Tipo de hogar: Padre o madre solo/a que conviva con algún hijo & 95341 & 75,2 & 88,2 \\
\hline Tipo de hogar: Pareja con hijos que convivan en el hogar & 317098 & 92,7 & 97,9 \\
\hline Total viviendas CASTILLA-LA MANCHA & 690719 & 74,2 & 86,8 \\
\hline Tipo de hogar: Padre o madre solo/a que conviva con algún hiio & 63325 & 68,3 & 91,5 \\
\hline Tipo de hogar: Pareja con hijos que convivan en el hogar & 308440 & 91,3 & 96,5 \\
\hline Total viviendas CATALUÑ̃A & 2645878 & 84,9 & 94,0 \\
\hline Tipo de hogar: Padre o madre solo/a que conviva con algún hijo & 307807 & 87,5 & 94,8 \\
\hline Tipo de hogar: Pareja con hijos que convivan en el hogar & 1032767 & 92,7 & 97,7 \\
\hline Total viviendas COMUNITAT VALENCIANA & 1782215 & 80,0 & 90,6 \\
\hline Tipo de hogar: Padre o madre solo/a que conviva con algún hiijo & 217097 & 81,0 & 93,5 \\
\hline Tipo de hogar: Pareja con hijos que convivan en el hogar & 716344 & 92,7 & 96,9 \\
\hline Total viviendas EXTREMADURA & 373468 & 74,7 & 89,3 \\
\hline Tipo de hogar: Padre o madre solo/a que conviva con algún hiīo & 39983 & 75,8 & 91,8 \\
\hline Tipo de hogar: Pareja con hijos que convivan en el hogar & 148603 & 92,3 & 98,4 \\
\hline Total viviendas GALICIA & 967264 & 73,3 & 88,8 \\
\hline Tipo de hogar: Padre o madre solo/a que conviva con algún hijo & 121534 & 73,9 & 94,6 \\
\hline Tipo de hogar: Pareja con hijos que convivan en el hogar & 321567 & 89,0 & 97,2 \\
\hline Total viviendas COMUNIDAD DE MADRID & 2336249 & 87,8 & 94,5 \\
\hline Tipo de hogar: Padre o madre solo/a que conviva con algún hijo & 283476 & 94,0 & 95,9 \\
\hline Tipo de hogar: Pareja con hijos que convivan en el hogar & 911112 & 95,6 & 98,4 \\
\hline Total viviendas REGIÓN DE MURCIA & 488426 & 78,1 & 91,3 \\
\hline Tipo de hogar: Padre o madre solo/a que conviva con algún hijo & 49100 & 85,2 & 89,5 \\
\hline Tipo de hogar: Pareja con hijos que convivan en el hogar & 225785 & 92,0 & 98,1 \\
\hline Total viviendas COMUNIDAD FORAL DE NAYARRA & 221808 & 87,5 & 95,0 \\
\hline Tipo de hogar: Padre o madre solo/a que conviva con algún hiio & 22311 & 89,8 & 91,1 \\
\hline Tipo de hogar: Pareja con hijos que convivan en el hogar & 95686 & 95,7 & 99,2 \\
\hline Total viviendas PAÍS VASCO & 791680 & 83,2 & 91,5 \\
\hline Tipo de hogar: Padre o madre solo/a que conviva con algún hijo & 91889 & 82,1 & 89,2 \\
\hline Tipo de hogar: Pareja con hijos que convivan en el hogar & 300168 & 95,9 & 98,3 \\
\hline
\end{tabular}




\begin{tabular}{lccc}
\hline & $\begin{array}{c}\text { TOTAL } \\
\text { VIVIENDAS }\end{array}$ & $\begin{array}{c}\text { VIVIENDAS CON ALGÚN } \\
\text { TIPO DE ORDENADOR }\end{array}$ & $\begin{array}{c}\text { VIVIENDAS } \\
\text { QUE DISPONEN DE ACCESO } \\
\text { A INTERNET }\end{array}$ \\
\hline Total viviendas LA RIOJA & 113327 & 78,4 & 90,6 \\
\hline Tipo de hogar: Padre o madre solo/a que conviva con algún hijo & 11870 & 75,9 & 91,0 \\
\hline Tipo de hogar: Pareja con hijos que convivan en el hogar & 41338 & 95,5 & 98,3 \\
\hline Total viviendas ClUDAD AUTÓNOMA DE CEUTA & 18607 & 86,3 & 91,7 \\
\hline Tipo de hogar: Padre o madre solo/a que conviva con algún hijo & 490 & 100,0 & 100,0 \\
\hline Tipo de hogar: Pareja con hijos que convivan en el hogar & 8565 & 100,0 & 100,0 \\
\hline Total viviendas ClUDAD AUTÓNOMA DE MELILLA & 29954 & 82,2 & 91,2 \\
\hline Tipo de hogar: Padre o madre solo/a que conviva con algún hijo & 5040 & 52,1 & 76,4 \\
\hline Tipo de hogar: Pareja con hijos que convivan en el hogar & 13255 & 93,8 & 100,0 \\
\hline
\end{tabular}

Unidades: $\mathrm{n}^{\circ}$ de viviendas (con al menos un miembro de 16 a 74 años).

Fuente: INE (2019). Encuesta sobre Equipamiento y Uso de Tecnologías de Información y Comunicación en Hogares (TIC-H’19).

Así, los desiguales niveles de renta, los diferentes niveles de estudio y las tipologías del hogar afectan en desigual medida a las carencias materiales de ordenador en los hogares. Esta cuestión es determinante porque alumbra la idea de desigualdad social y territorial, al tiempo que la imposibilidad para algunos estudiantes que viven en hogares de bajas rentas (más cuando solo viven con madre o con padre) y con bajo nivel de estudios (variables muy asociadas) de acceder a un modelo educativo virtual telemático.

En la tabla I hemos visto que el $82 \%$ de las viviendas de familias monoparentales con algún hijo tienen algún ordenador en casa. Un 18\% no lo tiene y supone que del total de hogares (1 909 021), 343624 con niños no tienen ordenador en casa. Hemos visto también que el 93,1\% de los hogares con pareja y al menos un niño tienen algún ordenador en casa. Un 6,9\% no lo tiene y supone que del total de hogares (6498914) 448425 con niños no tienen ordenador en casa. En adición, hay un total de 792049 hogares en España de familias con niños sin ordenador en casa.

Esta situación se asocia también al porcentaje de usuarios de 16 a 74 años que alguna vez han utilizado internet $(87,3 \%)$ que varía por nivel de formación (cercano al 100\% con los que alcanzan nivel universitario o mayor que los niveles obligatorios de enseñanza (justamente más proporción en el Norte, sin Galicia) y por Comunidades Autónomas ( $91,4 \%$ en Madrid en lo alto por 82,6\% en Castilla-La Mancha, $83,1 \%$ en Galicia y $83,7 \%$ en Extremadura), que se ve en la tabla III que sigue.

\section{Tabla III. Porcentaje de usuarios ( 16 a 74 años) que alguna vez han utilizado internet por nivel de formación y comunidad autónoma. Año 2018}

\begin{tabular}{|c|c|c|c|c|c|c|c|c|}
\hline & TOTAL & $\begin{array}{l}\text { EDUCACIÓN } \\
\text { PRIMARIA }\end{array}$ & $\begin{array}{c}\text { EDUCACIÓN } \\
\text { SECUNDARIA } \\
1 .^{a} \text { ETAPA }\end{array}$ & $\begin{array}{c}\text { EDUCACIÓN } \\
\text { SECUNDARIA } \\
2 .^{a} \text { ETAPA }\end{array}$ & $\begin{array}{l}\text { F.P. DE } \\
\text { GRADO } \\
\text { SUPERIOR }\end{array}$ & $\begin{array}{l}\text { DIPLOMATURA } \\
\text { UNIVERSITARIA Y } \\
\text { EQUIVALENTES }\end{array}$ & $\begin{array}{c}\text { LICENCIATURA } \\
\text { UNIVERSITARIA, } \\
\text { MÁSTER } \\
\text { Y EQUIVALENTES }\end{array}$ & $\begin{array}{l}\text { DOCTORADO } \\
\text { UNIVERSITARIO }\end{array}$ \\
\hline TOTAL & 87,3 & 57,1 & 87,3 & 96,0 & 97,9 & 98,2 & 99,2 & 98,9 \\
\hline Andalucía & 86,0 & 64,0 & 88,5 & 98,1 & 94,9 & 99,4 & 100,0 & 100,0 \\
\hline Aragón & 90,5 & 66,7 & 89,3 & 97,0 & 97,3 & 97,9 & 99,6 & 100,0 \\
\hline Asturias , Principado de & 87,2 & 54,6 & 84,2 & 94,8 & 99,1 & 98,0 & 99,5 & 100,0 \\
\hline Balears, Illes & 90,4 & 72,3 & 89,5 & 94,8 & 100,0 & 100,0 & 99,0 & 100,0 \\
\hline Canarias, Islas & 85,8 & 67,4 & 85,3 & 95,8 & 100,0 & 100,0 & 100,0 & 100,0 \\
\hline Cantabria & 84,5 & 37,4 & 84,2 & 92,3 & 91,7 & 96,5 & 99,5 & 100,0 \\
\hline
\end{tabular}




\begin{tabular}{|c|c|c|c|c|c|c|c|c|}
\hline & TOTAL & $\begin{array}{l}\text { EDUCACIÓN } \\
\text { PRIMARIA }\end{array}$ & $\begin{array}{c}\text { EDUCACIÓN } \\
\text { SECUNDARIA } \\
1 .^{\circ} \text { ETAPA }\end{array}$ & $\begin{array}{c}\text { EDUCACIÓN } \\
\text { SECUNDARIA } \\
2 .^{a} \text { ETAPA }\end{array}$ & $\begin{array}{c}\text { F.P. DE } \\
\text { GRADO } \\
\text { SUPERIOR }\end{array}$ & $\begin{array}{l}\text { DIPLOMATURA } \\
\text { UNIVERSITARIA Y } \\
\text { EQUIVALENTES }\end{array}$ & $\begin{array}{c}\text { LICENCIATURA } \\
\text { UNIVERSITARIA, } \\
\text { MÁSTER } \\
\text { Y EQUIVALENTES }\end{array}$ & $\begin{array}{c}\text { DOCTORADO } \\
\text { UNIVERSITARIO }\end{array}$ \\
\hline Castilla y León & 84,9 & 54,1 & 82,5 & 96,2 & 98,3 & 97,5 & 98,9 & 100,0 \\
\hline Castilla-La Mancha & 82,6 & 55,6 & 87,2 & 97,2 & 97,2 & 97,1 & 98,1 & 100,0 \\
\hline Cataluña & 88,6 & 53,5 & 89,6 & 95,9 & 98,7 & 98,1 & 99,5 & 100,0 \\
\hline Comunitat Valenciana & 87,2 & 45,4 & 88,4 & 95,1 & 99,4 & 100,0 & 99,5 & 100,0 \\
\hline Extremadura & 83,7 & 44,2 & 88,0 & 95,9 & 95,4 & 97,1 & 100,0 & 100,0 \\
\hline Galicia & 83,1 & 49,5 & 81,8 & 95,0 & 97,8 & 95,2 & 100,0 & 100,0 \\
\hline Madrid, Comunidad de & 91,4 & 64,1 & 87,8 & 96,8 & 99,5 & 98,7 & 98,4 & 100,0 \\
\hline Murcia, Región de & 86,8 & 64,8 & 88,9 & 94,5 & 99,4 & 97,7 & 98,7 & 96,5 \\
\hline Navarra, Com. Foral & 88,8 & 48,1 & 88,2 & 93,4 & 98,7 & 100,0 & 100,0 & 100,0 \\
\hline País Vasco & 87,5 & 47,6 & 85,0 & 92,7 & 97,4 & 92,7 & 98,6 & 100,0 \\
\hline Rioja, La & 84,8 & 58,7 & 76,6 & 96,7 & 99,4 & 97,4 & 97,0 & 100,0 \\
\hline Ceuta & 85,9 & 77,0 & 67,7 & 98,6 & 100,0 & 100,0 & 100,0 & 100,0 \\
\hline Melilla & 89,3 & 73,8 & 100,0 & 100,0 & 100,0 & 100,0 & 100,0 & $\ldots$ \\
\hline
\end{tabular}

NOTA: procede de la Encuesta sobre Equipamiento y Uso de Tecnologías de Información y Comunicación en Hogares. INE. 2018. Fuente: MEyFP (2020). Las cifras de la educación en España. Curso 17-18. Indicador F2.7.

Los microdatos del Centro de Investigaciones Sociológicas (CIS) con muestras de 2500 entrevistados/as (de 18 años y más) proporcionan también pistas sobre el uso de internet y la disponibilidad de dispositivos electrónicos, así como sobre su variabilidad por condición socioeconómica, hijos en la vivienda, niveles de estudio y otras variables, de forma conjunta. El análisis es en parte especulativo-hipotético porque la múltiple desagregación minora el tamaño muestral e invalida la inferencia estadística. Veamos las certezas primero. Un 74,8 \% de personas señaló en el barómetro 3213 de mayo de 2018 del CIS haber utilizado internet en los últimos tres meses (pregunta, P24) ${ }^{5}$. Casi idéntica proporción a los que señalan tener conexión a internet (75,8\%; pregunta P26) o tener teléfono fijo (77,4\%). Menor es, sin embargo, la proporción de personas que señala en el estudio del CIS tener ordenador en casa $(68 \%)$ o tableta $(43,9 \%)$ y menor aún, los que indican tener una Smart TV (63,7\%) o una consola de videojuegos (31,6\%); mientras que la mayoría tiene móvil $(92,5 \%)$ como se observa en la tabla IV que sigue.

\section{Tabla IV. Proporción de entrevistados (\% verticales para cada dispositivo) que dispone en su domicilio de smart TV, ordenador personal, teléfono fijo, teléfono móvil, conexión a internet, tableta, consola de videojuegos}

\begin{tabular}{lccc}
\hline & \multicolumn{1}{c}{ TIENE EN SU DOMICILIO } & RECUENTO & $\%$ VERTICAL \\
\hline \multirow{2}{*}{ Smart TV } & Sí (sí menciona) & 900 & $36,3 \%$ \\
\hline \multirow{2}{*}{ Ordenador personal } & NO (no menciona) & 1581 & $63,7 \%$ \\
\hline \multirow{2}{*}{ Teléfono fijo } & Sí (sí menciona) & 1687 & $68,0 \%$ \\
\hline \multirow{2}{*}{ Teléfono móvil } & NO (no menciona) & 794 & $32,0 \%$ \\
\hline
\end{tabular}

5 La proporción era de un 76,5\% en el barómetro del CIS 3195 de noviembre de 2017 (pregunta P21). 


\begin{tabular}{|c|c|c|c|}
\hline \multicolumn{2}{|c|}{ TIENE EN SU DOMICILIO } & \multirow{2}{*}{$\begin{array}{c}\text { RECUENTO } \\
1881\end{array}$} & \multirow{2}{*}{$\begin{array}{c}\% \text { VERTICAL } \\
75,8 \%\end{array}$} \\
\hline Conprín olntornet & Sí (sí menciona) & & \\
\hline Conexion a minernel & NO (no menciona) & 600 & $24,2 \%$ \\
\hline \multirow{2}{*}{ Tableta } & Sí (sí menciona) & 1088 & $43,9 \%$ \\
\hline & NO (no menciona) & 1393 & $56,1 \%$ \\
\hline \multirow{2}{*}{ Consola de videojuegos } & Sí (sí menciona) & 785 & $31,6 \%$ \\
\hline & NO (no menciona) & 1696 & $68,4 \%$ \\
\hline
\end{tabular}

Fuente: elaboración propia con microdatos del CIS 3213 (barómetro mayo de 2018). P26 (múltiples preguntas dicotómicas).

El archivo público de datos del CIS (los microdatos) permite adentrarse en una información más detallada y pormenorizada de los entrevistados que tienen niños menores de edad en sus hogares. En estos casos la disponibilidad de ordenadores sube al 84,7\%; la conexión a internet al 92,7\% y la disponibilidad de una tableta al $66,6 \%$, con variabilidad significativa respecto a los que no tienen hijos, como se ve en la tabla $\mathrm{V}$ que sigue.

Tabla V. Tabla cruzada de tenencia en domicilio de ordenador, conexión a internet y tableta, de entrevistado-a, por tenencia de hijos en casa. $N=2472$ entrevistados-as

\begin{tabular}{|c|c|c|c|c|c|}
\hline \multicolumn{6}{|c|}{ ORDENADOR } \\
\hline & & & $\begin{array}{c}\text { Sí } \\
\text { (sí menciona) }\end{array}$ & $\begin{array}{c}\text { No } \\
\text { (no menciona) }\end{array}$ & Total \\
\hline \multirow{4}{*}{ Tenencia de hijos menores de edad } & \multirow{2}{*}{ sí } & $\mathrm{N}$ & 555 & 100 & 655 \\
\hline & & $\%$ & $84,7 \%$ & $15,3 \%$ & $100,0 \%$ \\
\hline & \multirow{2}{*}{ № } & $\mathrm{N}$ & 1128 & 689 & 1817 \\
\hline & & $\%$ & $62,1 \%$ & $37,9 \%$ & $100,0 \%$ \\
\hline \multirow{2}{*}{ Total } & & n & 1683 & 789 & 2472 \\
\hline & & $\%$ & $68,1 \%$ & $31,9 \%$ & $100,0 \%$ \\
\hline \multicolumn{6}{|c|}{ CONEXIÓN A INTERNET } \\
\hline & & & $\begin{array}{c}\text { Sí } \\
\text { (si menciona) }\end{array}$ & $\begin{array}{c}\text { No } \\
\text { (no menciona) }\end{array}$ & Total \\
\hline \multirow{4}{*}{ Tenencia de hijos menores de edad } & \multirow{2}{*}{ sí } & $\mathrm{N}$ & 607 & 48 & 655 \\
\hline & & $\%$ & $92,7 \%$ & $7,3 \%$ & $100,0 \%$ \\
\hline & \multirow{2}{*}{ № } & N & 1269 & 548 & 1817 \\
\hline & & $\%$ & $69,8 \%$ & $30,2 \%$ & $100,0 \%$ \\
\hline \multirow{4}{*}{ Total } & & $n$ & 1876 & 596 & 2472 \\
\hline & & $\%$ & $75,9 \%$ & $24,1 \%$ & $100,0 \%$ \\
\hline & \multicolumn{4}{|c|}{ TABLETA } & \\
\hline & & & $\begin{array}{c}\text { Sí } \\
\text { (sí menciona) }\end{array}$ & $\begin{array}{c}\text { No } \\
\text { (no menciona) }\end{array}$ & Total \\
\hline \multirow{4}{*}{ Tenencia de hijos menores de edad } & \multirow{2}{*}{ sí } & N & 436 & 219 & 655 \\
\hline & & $\%$ & $66,6 \%$ & $33,4 \%$ & $100,0 \%$ \\
\hline & \multirow{2}{*}{ № } & N & 648 & 1169 & 1817 \\
\hline & & $\%$ & $35,7 \%$ & $64,3 \%$ & $100,0 \%$ \\
\hline \multirow{2}{*}{ Total } & & $n$ & 1084 & 1388 & 2472 \\
\hline & & $\%$ & $43,9 \%$ & $56,1 \%$ & $100,0 \%$ \\
\hline
\end{tabular}

ORDENADOR: $\mathrm{x}^{2}=114$ significativo (p-valor<.000). CONEXIÓN INTERNET: $\mathrm{x}^{2}=137$ significativo (p-valor<.000).TABLETA: $\mathrm{x}^{2}=187$ significativo ( $\mathrm{p}$-valor<.000).

Fuente: elaboración propia con microdatos del CIS 3213 (barómetro mayo de 2018). P26 (preguntas múltiples). 
Si precisamos más y desagregamos las proporciones de los entrevistados que tienen hijos de menor edad por su nivel de estudio y su estatus socioeconómico (el usado por el CIS), observamos que la tenencia de ordenador alcanza el 84,7\%, la conexión a internet el 75,9\% y la tenencia de tableta al 43,9\%. Estos porcentajes bajan en las familias con estudios obligatorios casi un $10 \%$ en el caso de los ordenadores, un 4,5\% en la conexión a internet y un $12,1 \%$ en la tenencia de tabletas. Igual ocurre con el estatus socioeconómico, aunque más pronunciado: las familias con hijos donde el cabeza de familia es un trabajador no cualificado cuentan con un 13,1\% menos de ordenadores en casa un 6,3\% menos de conexión a internet y 10,9\% menos de tabletas. En definitiva, más recursos en las familias con hijos de niveles educativos mayores que los obligatorios y con estatus socioeconómico de clases altas y medias altas, con distancias en los intervalos que alcanzan un $20 \%$ entre ellas en la tenencia de tabletas, en la tenencia de ordenadores y un $10 \%$ en la conexión a internet, tal y como se ve en la tabla VI que sigue.

\section{Tabla VI. Entrevistados-as con hijos-as y tenencia en domicilio de ordenador, conexión a internet y/o tableta, por estudios del entrevistado-a y por estatus socioeconómico del CIS}

\begin{tabular}{|c|c|c|}
\hline \multirow[t]{2}{*}{ SÍ menciona que tiene ORDENADOR } & & $68,1 \%$ \\
\hline & Tiene ORDENADOR y tiene hijos & $84,7 \%$ \\
\hline \multirow{3}{*}{ Estudios } & obligatorios & $75,5 \%$ \\
\hline & post-obligatorios & $87,1 \%$ \\
\hline & superiores & $92,9 \%$ \\
\hline \multirow{5}{*}{ Estatus socioeconómico CIS } & clases altas/medias altas & $92,4 \%$ \\
\hline & nuevas clases medias & $88,6 \%$ \\
\hline & viejas clases medias & $90,7 \%$ \\
\hline & trabajadores cualificados & $74,8 \%$ \\
\hline & trabajadores no cualificados & $71,6 \%$ \\
\hline \multirow[t]{2}{*}{ SÍ menciona que tiene CONEXIÓN A INTERNET } & & $75,9 \%$ \\
\hline & Tiene CONEXIÓN A INTERNET y tiene hijos & $92,7 \%$ \\
\hline \multirow{3}{*}{ Estudios } & obligatorios & $88,2 \%$ \\
\hline & post-obligatorios & $95,6 \%$ \\
\hline & superiores & $94,5 \%$ \\
\hline \multirow{5}{*}{ Estatus socioeconómico CIS } & clases altas/medias altas & $96,2 \%$ \\
\hline & nuevas clases medias & $96,2 \%$ \\
\hline & viejas clases medias & $93,3 \%$ \\
\hline & trabajadores cualificados & $88,1 \%$ \\
\hline & trabajadores no cualificados & $86,4 \%$ \\
\hline \multirow[t]{2}{*}{ SÍ menciona que tiene TABLETA } & & $43,9 \%$ \\
\hline & Tiene TABLETA y tiene hijos & $66,6 \%$ \\
\hline \multirow{3}{*}{ Estudios } & obligatorios & $54,5 \%$ \\
\hline & post-obligatorios & $69,8 \%$ \\
\hline & superiores & $77,5 \%$ \\
\hline \multirow{5}{*}{ Estatus socioeconómico CIS } & clases altas/medias altas & $74,7 \%$ \\
\hline & nuevas clases medias & $71,2 \%$ \\
\hline & viejas clases medias & $70,7 \%$ \\
\hline & trabajadores cualificados & $54,8 \%$ \\
\hline & trabajadores no cualificados & $55,7 \%$ \\
\hline
\end{tabular}

Fuente: elaboración propia con microdatos del CIS 3213 (barómetro mayo de 2018). P26 (preguntas múltiples). 
En síntesis, todas las encuestas producen información que avala que los hogares con más rentas, con más estudios, con más estatus y ubicados en unas determinadas Comunidades Autónomas marcan situaciones evidentes de desigualdad en tenencia de ordenadores en sus hogares, de conexión a internet y de tableta. Ratifica, en consecuencia, las afecciones diferenciales y desiguales del cierre de los centros escolares. Veamos seguidamente esta situación con más detenimiento y cómo afecta a la escolarización diferencial por centros.

\section{Alumnado afectado por el cierre de los centros escolares}

Hemos constatado ya que la proporción de hogares sin ordenador en familias que tenían niños alcanzaba la cifra de 343624 en el caso de niños viviendo en hogares monoparentales y que ascendía a 448425 en hogares con pareja y al menos un niño, dando un total de 792049 hogares en España de familias con niños que no cuentan con ordenador.

Múltiples declaraciones en prensa, radio, o televisión, resaltan la relevancia de estas cifras que impiden el seguimiento telemático de las clases online para un número relevante del alumnado. La Ministra de Educación y Formación Profesional, Isabel Celaá, calcula que un 14\% del alumnado no se conecta a la enseñanza virtual y que este porcentaje varía por Comunidades Autónomas (Orio, 2020). Si aceptamos este $14 \%$ referencial, supone que, solo en la enseñanza primaria y secundaria tenemos cerca de un millón de alumnos afectados (910000 $=14 \%$ de los 6,5 millones de estudiantes).

El analista de educación del Banco Mundial, Lucas Gortázar, cifra este porcentaje en torno al 10\%. Así lo señaló en una entrevista realizada por Pepa Bueno en la Cadena Ser: «en España hay un 10\% de familias sin ordenadores en casa y sin conexión a internet, agravando la desigualdad». Igual consideración le merece a Ricardo Ibarra, Director de la Plataforma por la Infancia. En una entrevista de radio realizada por Íñigo Alfonso en las Mañanas de Radio Nacional de España (07-04-2020), indica que en España al menos medio millón de niños no puede seguir el curso escolar por vía telemática, problema creciente porque se amplía el número de familias vulnerables con la pérdida de trabajos y rentas. Y así lo señala también Andrés Conde, Director de Save The Children, en un Programa anterior de Íñigo Alfonso en RNE de 27-03-2020, reseñando que las familias desfavorecidas son ahora más porque muchas han perdido sus empleos o han visto reducida su actividad. Añade que un $60 \%$ de las 2000 familias a las que le realizaron una encuesta telefónica, familias con las que trabajan habitualmente en los programas de lucha contra la pobreza, han perdido su empleo y sus rentas, viviendo ahora de la economía informal y con un aumento de estrés familiar y hacinamiento (conviven en casas de pequeñas superficies y sin luz natural). Sigue comentando que casi la mitad de los niños en situación de pobreza no dispone de dispositivo electrónico alguno en casa para acceder a la educación a distancia y que, en esos casos, se ha interrumpido su proceso educativo (brecha educativa). Señala, finalmente, que esta situación afecta a un millón de niños en España que se encuentra en pobreza severa y a casi 2 millones de niños que se encuentran en riesgo de pobreza y exclusión.

Puestos en contacto por correo electrónico y móvil con el Instituto de Enseñanza Secundaria (IES) La Laboral de La Laguna ${ }^{6}$, el mayor IES de Canarias; su Director, Fernando González Villavecchia,

\footnotetext{
Este Instituto es el mayor de Canarias por volumen de alumnado, con 1884 estudiantes, 128 docentes y 66 grupos de ESO, Bachillerato, Formación Profesional Básica, Ciclos Formativos de Grados Medio y Superior. Cuenta con turnos de mañana, tarde y noche. El IES comparte espacios comunes con la Residencia Escolar Pedro García Cabrera con capacidad para 300 alumnos de distintos municipios de Tenerife y del resto de las islas (Mercedes Cabrera es la Directora de la Residencia).
} 
señala que alrededor del 10\% del alumnado de su Instituto no dispone de dispositivo en casa para el seguimiento telemático de las clases, constatado por los tutores. A este alumnado, añade, le están enviando dispositivos del propio Instituto ${ }^{8}$. Nos indica también que prácticamente la totalidad del alumnado dispone de móvil, pero que no es de utilidad para un seguimiento continuado y diario de la enseñanza online. El IES ha instaurado desde hace tres años un correo corporativo para contactar y dar instrucciones a todo el alumnado de su centro y con la aplicación MiColegioApp puede contactar rápidamente con las familias y un Plan de Formación de Centro destinado al profesorado ha acercado a las docentes al uso de las nuevas tecnologías en el aula (GSuite, Classroom, Additio, MiColegioAPP), asumiendo asimismo el IES la licencia del Programa de Gestión de Aulas ADDITIO para todo el profesorado. El uso de tabletas electrónicas, adquiridas el pasado curso, está extendiendo las tareas y los modelos de aprendizaje con ellas.

Una alumna de $2^{\circ}$ curso de Bachillerato de un Centro Privado Religioso de Santa Cruz de Tenerife (Pureza de María), que quiere guardar el anonimato, nos dice que desde que estaba en $1^{\circ}$ de la ESO en ese centro llevaba a clase una tableta, como la mayoría de los alumnos de ese curso (90) y los pocos que no la llevaban (10) tenían una facilitada por el centro. En la actualidad, sigue diciendo, todos los alumnos de Bachillerato disponen de una tableta en clase, móvil con grupos de WhatsApp por cada clase de Bachillerato y por curso de todas las clases, usando uno u otro con los delegados y subdelegados de los cursos como vía de comunicación inmediata con el profesorado. Cuentan con un correo electrónico corporativo del centro desde el que reciben instrucciones generales de la dirección y/o particulares de tutores o profesores de las distintas materias. Cuentan además con aulas virtuales que vienen usando desde $1^{\circ}$ de la ESO, subiendo tareas habitualmente, cada semana. Todos los alumnos de $2^{\circ}$ de Bachillerato reciben enseñanza telemática con Google Meet diariamente, de una o varias materias. Añade, asimismo, que compañeros de otros centros de su entorno, también privados (religiosos o no) y con similar número de alumnos, están en condiciones parecidas a la suya. La alumna pertenece al único centro reconocido en Canarias como Referente School por Google (https://pmaria-santacruz.com/2018/11/pureza-de-maria-santa-cruz-uni-

\footnotetext{
Coincide en porcentaje exactamente con la estimación realizada por el Ministerio de Educación y Formación Profesional que recoge Zafra (2020).

8 El IES San Benito del Municipio de La Laguna anunció el 27-03-20 en su cuenta de Twitter que tiene preparado 40 dispositivos electrónicos para facilitárselos como préstamo a familias con escasez de recursos o con varios hijos, mientras dure esta situación (ver y oír vídeo en Twitter: https://twitter.com/iessanbenito/ status/1243511445410787329). Un tweet posterior de 3 de abril anuncia (https://twitter.com/iessanbenito/status/1246045791547949056) que ya han repartido las primeras 10 tabletas a alumnado con escasez de recursos gracias a Protección Civil La Laguna.

Esta acción se ha extendido a nivel de Canarias. El Director General de Innovación Educativa de la Consejería de Educación del Gobierno de Canarias, Gregorio Cabrera, anunció (13-04-20) la distribución inmediata de tabletas en el Archipiélago, comenzando por el alumnado de Bachillerato y FP (Twitter: @EducacionCan; https://twitter.com/EducacionCan/status/1249783486292131842).

También en la Comunidad de Madrid han adoptado esta política de distribución de 1000 tabletas de forma inmediata, acción que a Jesús Rogero (13-04-20; @, jesusrogero) le parece totalmente insuficiente al tener la Comunidad de Madrid más de 900000 jóvenes entre 6 y 18 años y que al menos un $13 \%$ de ellas (unas 117000 ) necesitarían este dispositivo que solo cubre un $0,85 \%$ (https://twitter.com/jesusrogero/status/1249806249161568256).

Iniciativas parecidas, incluso a nivel personal, hemos podido oír, ver y/o leer en estos tiempos de coronavirus. Es el caso de José García, profesor de Tecnología en el IES Francisco Romero Vargas, de Jerez de la Frontera. Almoguera (2020) recoge una biografía de este profesor, nacido en el barrio gaditano de La Viña, que esquivó su destino social gracias al empeño de sus padres que hizo posible que pudiese ir a la Universidad y escapar al futuro marcado por el código postal. Con 45 años es profesor en un IES complicado socialmente donde cada progreso educativo es una victoria. Por eso, cuando supo que uno de sus estudiantes no podría seguir las clases tras decretarse el estado de alarma, no dudó en pagarle de su bolsillo la conexión de internet para no perderlo (su IES no podía gestionar con rapidez este problema). Sigue el relato con un sinfín de adecuaciones de su hogar para trabajar telemáticamente con su alumnado. Cuenta con una singular pizarra que combina con recursos informáticos como Zoom -sin duda alouna, la aplicación del confinamiento, porque permite hasta un centenar de videoconferencias simultáneas-, Google Classroom o Moodle, recomendado por Educación, pero cuyo manejo «es más complicado». Añade que la asignatura condiciona el desarrollo de la clase y la forma de impartirla. Explica que hay profesores de Historia que únicamente precisan de una webcam, mientras que una compañera suya utiliza una red social como Instagram para explicar las lecciones.

Otro docente de secundaria, Carlos Candel (2020), señala que más de la mitad de su grupo de clase, todos ellos mayores de 16 años, no cuenta con un ordenador para hacer las tareas, que un tercio no dispone de la conexión a Internet necesaria para poder realizar un seguimiento óptimo del trabajo a través de la red y que uno de ellos ni siquiera cuenta con un móvil para mantener una comunicación diaria con nosotros, sus tutores. Y a todo esto se le suma que el cien por cien de sus alumnos no tiene el apoyo suficiente en sus casas como para generar los hábitos que se requieren para estos nuevos tiempos de educación remota.

La falta de seguimiento de las clases telemáticas es una de las principales preocupaciones de los docentes para evitar que aumente el absentismo, lo que ha transformado a los tutores en cuasi detectives que tratan de localizar a los alumnos que no dan señales, quienes reconocen que han perdido la pista a más de 50 de sus estudiantes y las dificultades que tienen para localizarlos. Zafra (2020) también se hace eco de la pérdida de alumnado y de las dificultades para muchos de entregar seguir las clases y entregar las tareas. Un reciente informe de la UNESCO (2020) confirma estas preocupaciones del profesorado y alerta sobre el abandono escolar que puede causar la prolongación del cierre educativo.
} 
co-google-reference-school-en-canarias/) con un Departamento TIC liderado por Fernando Lemus, contando con apoyo del Equipo Directivo y del Claustro de Profesores.

En la enseñanza Primaria las cosas son más complejas para la enseñanza telemática. Una madre del Centro de Enseñanza de Infantil y Primaria El Chapatal (CEIP), ubicado en el centro de Santa Cruz de Tenerife, con hijas en $2^{\circ}$ y $5^{\circ}$ de Primaria, nos dice que los padres están actuando como educadores y participan activamente en el proceso de aprendizaje. Reciben por correo electrónico notificaciones para realización de tareas de sus hijos para las distintas materias, que después remiten a los tutores o profesores vía mail. El problema, nos dice, es que algunos padres tienen más posibilidades que otros para ayudar a sus hijos y que algunos están mucho más familiarizados con el trabajo telemático, su caso, al trabajar para una oficina bancaria. En la web del centro (http://www3.gobiernodecanarias.org/medusa/edublogs/ceipelchapatal/) pueden verse distintos enlaces por cursos de primaria para ver las tareas escolares cotidianas?.

La Federación de Enseñanza de Comisiones Obreras de Canarias eleva al 31\% el alumnado afectado por la brecha digital en Canarias (Diario de Avisos, 9-04-20) y en un comunicado público (2020) señala que en estos momentos es muy difícil garantizar derechos fundamentales básicos como los de igualdad, equidad y participación y la situación actual amplifica la brecha social y económica de las familias desfavorecidas, más aún con la brecha digital. Así lo recoge también Encinoso (2020) que incide en que las clases a distancia incrementan la brecha educativa en Canarias.

Los testimonios anteriores enfatizan la brecha digital, la carencia de ordenadores en los hogares y la insuficiente formación de los padres para ayudar en las tareas escolares a sus hijos y actuar, en el caso de la Enseñanza Primaria, como alumnos digitales en este período de confinamiento. No son los únicos. Desde la UNESCO (2020) se señalan los problemas de la enseñanza telemática por la falta de preparación de padres con niveles bajos de formación, además del desigual acceso a conexiones de internet en familias desfavorecidas. Tracey Burns (Senior Analyst, OECD Directorate for Education and Skills) confirma también estas impresiones. En un informe reciente sobre el impacto del coronavirus (OECD, 2020) señala que a medida que los sistemas educativos se mueven masivamente hacia el aprendizaje electrónico, la brecha digital en conectividad, acceso a dispositivos y niveles de habilidad adquiere más peso; de tal forma que las familias favorecidas tienen más probabilidades de tener padres con mayores niveles de habilidad digital que puedan apoyar el aprendizaje de los niños que no pueden asistir a la escuela; mientras que los estudiantes de familias menos acomodadas tienen menos probabilidades de tener este apoyo, lo que significa que corren el riesgo de quedarse atrás.

Las declaraciones de la alumna de $2^{\circ}$ de Bachillerato y los testimonios de los profesores de Primaria y Secundaria de los distintos centros públicos recogidos en el texto y en las notas a pie de página, evidencian que la brecha digital no es aleatoria y que dibuja escenarios diferentes para el alumnado de enseñanza pública y el alumnado de enseñanza privada. Y, efectivamente, los datos que veremos seguidamente avalan que la brecha digital (y social) no se restringe solo a territorios, rentas, tipologías de hogar y carencias de recursos, sino que la tipología de centros juega un papel relevante al escolarizar diferencialmente al

9 Similares comentarios pueden leerse en las entrevistas realizadas por Almoguera (2020). Así, recoge la opinión de Marcos Jiménez, maestro de $3^{\circ}$ y $4^{\circ}$ de Primaria en el CEIP Escultor César Molina Megías, en el municipio granadino de Churriana de la Vega. Envía tareas por correo electrónico y supervisa con los padres su realización, entre las numerosas cosas que deben hacer. Lo mismo señala Estefanía Segura, profesora de $5^{\circ}$ de Primaria en el CEIP Benyamina de Torremolinos (Málaga), también entrevistada por Almoguera (2020) que afirma que las jornadas se han vuelto maratonianas (en su caso más porque tiene 3 niños) y que, en Primaria, el seguimiento del alumnado depende notablemente de la implicación de los padres. Advierte que las necesidades de atención individualizada que precisa este tipo de enseñanza ralentiza el trabajo. 
alumnado por clases sociales ${ }^{10}$. En las tablas anteriores hemos visto que los hogares más afectados son los de rentas bajas (inferiores a 900 euros mensuales), los monoparentales, los que los padres tienen formación secundaria de primera etapa o menos y más los que viven en las Comunidades Autónomas del Sur (incluyendo a Galicia y Canarias).

Sabemos (gráfico 1 anterior) que la escolarización en España en los centros públicos alcanza al 67\% del alumnado en Infantil, Primaria, Secundaria Obligatoria, Bachillerato y Enseñanzas Profesionales (ciclos formativos), por el 33\% los privados (concertados o no), con notable y desigual representación por Comunidades Autónomas: más presencia privada porcentual en las Comunidades del Norte (con Madrid) que en las del Sur, con Canarias. La distribución del alumnado en los centros públicos-privados está asociada íntimamente al origen familiar del alumnado. En efecto, así se constata al visualizar la escolarización del alumnado en centros públicos y privados por clases sociales (usando como aproximación los estudios de su padre y de su madre como estratos de clasificación de clase). Cuando lo hacemos, la escolarización cambia sustancialmente, no solo por la ubicación de los centros (también diferencial y habitualmente más próximos a residencias de rentas altas [ver mapa interactivo por tipo de centros y rentas en El País, 2019]); sino porque en ellos los datos generales aleatorios de representación pública-privada cambian significativamente. Así puede contemplarse con una macro-muestra de segundo curso de secundaria obligatoria ${ }^{11}$ que rompe la aleatoriedad representativa pública-privada del $67 \%$ por $33 \%$, como vemos en la tabla VII que sigue. Obsérvese que en ella un 48,7\% de los hijos de madres con estudios superiores están escolarizados en la enseñanza privada, proporción que se eleva al 51,5\% cuando su padre tiene estudios superiores y, se eleva aún más, al 56,6\% cuando su padre y su madre tienen conjuntamente estudios superiores. Por el contrario, cuando tanto padre y madre tienen estudios secundarios básicos o menos, la escolarización de sus hijos en centros públicos sube del 67\% general al 77,1 \% (75,5\% caso de considerar solo la madre y $75,7 \%$ de considerar solo el padre).

\section{Tabla VII. Tabla cruzada de alumnado de $2^{\circ}$ de Secundaria Obligatoria (\% horizontales), por tipo de centro y niveles de estudio del padre y de la madre $\mathrm{N}=27805$ alumnos-as}

\begin{tabular}{|c|c|c|c|c|}
\hline \multicolumn{5}{|c|}{ TIPO DE CENTRO } \\
\hline & & Público & Privado & Total \\
\hline \multirow{3}{*}{ Estudios de la MADRE } & Secundarios obligatorios o menos & $75,5 \%$ & $24,5 \%$ & $100,0 \%$ \\
\hline & Secundarios superiores & $64,2 \%$ & $35,8 \%$ & $100,0 \%$ \\
\hline & Superiores & $51,3 \%$ & $48,7 \%$ & $100,0 \%$ \\
\hline \multirow{3}{*}{ Estudios del PADRE } & Secundarios obligatorios o menos & $75,7 \%$ & $24,3 \%$ & $100,0 \%$ \\
\hline & Secundarios superiores & $65,7 \%$ & $34,3 \%$ & $100,0 \%$ \\
\hline & Superiores & $48,5 \%$ & $51,5 \%$ & $100,0 \%$ \\
\hline & Total & $67,0 \%$ & $33,0 \%$ & $100,0 \%$ \\
\hline \multicolumn{2}{|c|}{ Total: padre y madre con estudios superiores ( $\mathrm{n}=3365$ ) } & $43,4 \%$ & $56,6 \%$ & $100,0 \%$ \\
\hline \multicolumn{2}{|c|}{ Total: padre y madre con estudios primarios ( $n=6662$ ) } & $77,1 \%$ & $22,9 \%$ & $100,0 \%$ \\
\hline
\end{tabular}

Fuente: elaboración propia con los microdatos de la EGD-2010 (IE-MECD, 2011.

10 Las diferencias entre centros públicos y privados tienen mucho que ver en España con las zonas de influencia de los centros para la escolarización. Los centros públicos ubicados en núcleos de población ricos en recursos (rentas declaradas por municipios, zonas y códigos postales (Agencia Tributaria, rentas por municipios y localidades: https://www.agenciatributaria.es/AEAT.internet/datosabiertos/catalogo/hacienda/Estadistica_de_los_declarantes_del_IRPF_por_municipios. shtml) se paraecen mucho más a los centros privados por el alumnado que tienen. De forma recíporoca, los centros privados ubicados en zonas de bajas rentas (son pocos) se parecen a los públicos en cuanto al alumnado y desaparecen sustncialmente las diferencias entre ellos.

11 Datos de la Evaluación General de Diagnóstico de $2^{\circ} \mathrm{ESO}$ de 2010, con muestras probabilísticas por comunidades autónomas de aproximadamente 1500 estudiantes, mas Ceuta y Melilla. La fusión de estas muestras para dar valores estatales para España y su consiguiente ponderación, bajan el error a menos del 0,5\%. 
No se trata solo de una brecha digital diferencial entre centros públicos y privados. Se trata también de la posible ayuda escolar diferencial que puedan aportar las familias (Burns, OECD, 2020; Schleicher, OECD, 2020; UNESCO, 2020), debilitada, cuando existe, en las familias de clase obrera (Pérez, Betancort y Cabrera, 2014). No es solo una cuestión de implicación familiar (Alonso Carmona, 2014), es un problema de capacidad de influencia, de motivación y de expectativas (Pérez, Betancort y Cabrera, 2013). La ayuda familiar en las tareas escolares en Primaria e incluso en Secundaria es ahora más relevante con el cierre escolar y niños y padres confinados en sus hogares. Los jóvenes que cuentan en sus hogares con padre y madre con niveles de instrucción elevados tienen no solo más recursos electrónicos, como hemos visto, sino más opciones de seguir la enseñanza telemática con ayuda de sus padres (Rogero, 2020). La Ministra de Educación y Formación Profesional, Isabel Celaá, lo reconoce indirectamente: «A los padres y las madres les estamos exigiendo un esfuerzo colosal, porque se han convertido en educadores de sus hijos las 24 horas, $y$ no solo de comportamiento personal. Muchos contenidos llegan telemáticamente a los alumnos y estos preguntan a sus padres cómo se bace, no lo entiendo, cómo se busca esa plataforma...» (Orio, 2020).

La docencia telemática ha obligado a reconvertir y adaptar las clases presenciales a clases online para la que parece que los centros privados también están más preparados. No todo el profesorado cuenta con la preparación suficiente para la docencia online. Algunos se han adaptado con la ayuda de otros compañeros del centro, al tiempo que escuchan y leen las críticas de algunos responsables políticos por su incompetencia tecnológica. Es el caso de la Consejera de Educación de Canarias, Mª José Guerra, que llama 'dinosaurios' a los docentes al no utilizar adecuadamente los recursos de las tecnologías con el alumnado (Méndez, 06-04-20). Y es que los sistemas educativos no están adaptados para la generalización de la enseñanza telemática (Rogero, 2020), aunque será una exigencia de futuro inmediato (Schleicher, OECD, 2020), con notables variaciones entre países y dentro de cada país.

El cierre escolar ha forzado una enseñanza telemática, pero la enseñanza no es solo aprendizaje (UNESCO, 2020). El cierre de las escuelas tiene profundos impactos en los estudiantes y en las comunidades enteras, desde el estrés y la ansiedad, a impactos en la nutrición para los estudiantes que dependen de los programas gratuitos de desayuno o almuerzo (Burns, 2020) y en la socialización (Parsons, 1959). La Ministra de Educación y Formación Profesional nos lo recuerda: «La escuela es insustituible, porque no solo proporciona conocimientos, sino también referentes: el del maestro, la convivencia con los alumnos de la misma edad... Educar es conocimiento más comportamiento» (Orio, 2020).

\section{Recapitulación y conclusiones}

La educación en España ha pasado de ser poco trascendente como problema social y/o personal (Cabrera, 2020) a ser con la Sanidad (ésta mucho más) una preocupación esencial de la sociedad española con la aparición del coronavirus. Algo más de diez millones de estudiantes, casi un millón de profesores y siete millones de familias se enfrentan al cierre escolar con confinamiento en los hogares y nuevas exigencias educativas. Los estudiantes afrontan la enseñanza telemática con desigual fortuna. Algunos disponen de ordenador (y/o tableta) y conexión a internet, pudiendo seguir las clases virtuales como una extensión de las presenciales. Otros carecen de opciones para ello. En general y a grandes rasgos, contar con una familia con recursos electrónicos, con formación superior, con padre y madre capacitados para ayudarles en sus tareas escolares, estar matriculado en un centro privado y en una región del Norte, mejora sustancialmente las opciones de seguir con menos dificultades la enseñanza telemática. Los profesores se enfrentan al cierre escolar readaptando sus programas de enseñanza presencial a un modelo virtual, 
cuando les es posible hacerlo y tienen competencias para ello. Parece que la gran mayoría del profesorado cuenta con estímulos positivos y con competencia tecnológica para la enseñanza online (con matices para algunas autoridades, padres y alumnos) o bien cuentan con apoyo de sus colegas para hacerla efectiva. Las familias, por su parte, se enfrentan al cierre escolar con desiguales recursos electrónicos y con diferentes capacidades de ayuda asociadas a su formación, principalmente.

Si bien todos los centros tienen el mismo problema al enfrentarse al cierre escolar, algunos se han adaptado de inmediato porque han propiciado la incorporación de los recursos virtuales y de los dispositivos electrónicos en sus clases desde hace años. Aunque solo disponemos de algunos testimonios puntuales y la certeza de la presencia desigual del alumnado en los centros por tipología familiar, todo parece indicar que los centros privados (más los ubicados en el centro de las ciudades y en los núcleos residenciales de mayor renta) están impartiendo enseñanza online sin más problemas que los que esta enseñanza tiene de por sí. Lo mismo podría pensarse de los centros públicos ubicados en similares zonas. Sin embargo, y en general, los centros públicos parecen estar en peores condiciones que los privados para afrontar la continuidad de la enseñanza por vía telemática, más por carencias de recursos del alumnado que acude a sus centros (falta de dispositivos electrónicos y conexión a internet) que, por falta de recursos del propio centro, que también, pero menos.

Un millón de estudiantes pueden estar afectados en España al carecer de recursos electrónicos para seguir las clases telemáticas. Las cifras bailan en función de las fuentes usadas. Quizás sean más y alcancen el 14\% que señala la Ministra de Educación. Las diferentes encuestas del INE, las del CIS y los registros del MEyFP, también los análisis que de ellas y ellos se hacen, reflejan que la desigualdad de oportunidades educativas aumenta al afectar más al alumnado de familias desfavorecidas y que empeora el diferencial de desigualdad de oportunidades existente cuando los centros estaban abiertos. Las respuestas de Tracey Burns para la OECD (2020), de Andreas Schleicher para la OECD (2020), de la UNESCO (2020) y de Sanz, Sáinz y Capilla para la OEI (2020) apuntan a ello al advertir y sugerir que las medidas políticas gubernamentales deben estar diseñadas para evitar la profundización de la desigualdad educativa y social y la brecha digital, más cuando los sistemas se mueven masivamente hacia el aprendizaje electrónico y la necesidad de contar con dispositivos electrónicos y acceso a internet se han vuelto imprescindibles.

Además del incremento de la desigualdad de oportunidades educativas entre jóvenes, nos enfrentamos al problema adicional, para todos, que causa el confinamiento y la falta real de relaciones interpersonales que debilitan la felicidad, la satisfacción personal con la vida, amplían la ansiedad y el estrés y agrian la conducta. La lectura positiva es que nos damos cuenta de la fragilidad de la vida y de la relevancia de la convivencia social para nuestra salud y felicidad. En el plano educativo nos obliga a tomar conciencia de los cambios que exige la educación telemática y la necesidad de acomodarnos y adaptarnos a la sociedad digitalizada como señala el Director del IES La Laboral de La Laguna, Fernando González Villavecchia. En ese sentido, hay que aprovechar los recursos de las comunicaciones inmediatas por WhatsApp (Zafra, 2020) como vía de comunicación usual del alumnado, al menos para el de secundaria, sabiendo que prácticamente todos los jóvenes de esta etapa educativa cuentan con un móvil smartphone y conexión a internet y que los de primaria tienen al menos padres en casa con móviles y formando parte de grupos de WhatsApp de padres, tutores y centros escolares.

Muchos retos pendientes le quedan por afrontar al sistema educativo en España. Uno de los principales es corregir en tiempos de penuria, paliar al menos, la desigualdad de oportunidades educativas en 
la que la brecha digital no es más que otra vertiente de la desigualdad. A ello hemos dedicado nuestra atención en este artículo.

\section{Referencias bibliográficas}

Alfonso, Íñigo (2020): Entrevista de radio realizada por Íñigo Alfonso en Las Mañanas de Radio Nacional de España, a Ricardo Ibarra (Director de la Plataforma por la Infancia). https://www.rtve.es/alacarta/audios/las-mananas-de-rne-con-inigo-alfonso/coronavirus-infancia-educacion-espana/5552958/, realizada el 7 de abril de 2020.

Alfonso, Íñigo (2020): Entrevista de radio realizada por Íñigo Alfonso el 27-03-2020, en Las Mañanas de Radio Nacional de España, a Andrés Conde (Director de Save The Children). https://www.rtve.es/ alacarta/audios/las-mananas-de-rne-con-inigo-alfonso/coronavirus-save-the-chidren-familias-vulnerables-espana/5546616/.

Almoguera, Pablo D. (2020): "Enseñar en tiempos de coronavirus. El profesor que pagó la conexión de internet a un alumno para no perderlo". El Mundo. Andalucía. https://www.elmundo.es/andalucia/2020/04/10/5e8f54a5fdddff99bb8b4609.html, consultado el 10 de abril de 2020.

Alonso Carmona, Carlos (2014): "Familia, Escuela y Clase Social: sobre los efectos perversos de la implicación familiar". Revista de la Asociación de Sociología de la Educación, RASE, 7 (2), 395-409. https:/ /ojs. uv.es/index.php/RASE/article/view/8778/8331.

Bueno, Pepa (2020): Entrevista a de radio realizada por Pepa Bueno en Hora 25, Cadena Ser, al analista de educación de Banco Mundial, Lucas Gortázar. Minutos de la entrevista de 22:17 a 27:45 (hora de 21:00 a 22:00). https://play.cadenaser.com/audio/cadenaser_hora25_20200402_210000_220000/, realizada el 2 de abril de 2020 .

Cabrera, Leopoldo (2020): "Is Education a Personal and/or Social Concern in Spain?" Revista de Educación, 388, 193-228. DOI: https://doi.org/10.4438/1988-592X-RE-2020-388-452.

Cabrera, Leopoldo (2020): Entrevista telefónica y por correo electrónico el 06-04-20 al Director del Instituto de Enseñanza Secundaria (IES) La Laboral, Fernando González Villavecchia. www.lalaboral.org. Director del IES La Laboral de La Laguna, Tenerife, Canarias.

Correos electrónicos: 38002791@gobiernodecanarias.orgy director@ieslalaboraldelalaguna.es Twitter:@LaboralLaguna; Facebook:@LaboralLaguna

Cabrera, Leopoldo (2020): Entrevista telefónica a una madre del CEIP El Chapatal de Santa Cruz de Tenerife y a una alumna de $2^{\circ}$ de Bachillerato del Centro Privado Religioso Pureza de María en Santa Cruz de Tenerife.

Cabrera, Leopoldo (2013): "Desigualdad social, rendimiento y logro educativos en España (1990-2012): Los desequilibrios regionales aumentan”. Revista de Estudios Regionales, 98, 15-49. Disponible en: http:// www.redalyc.org/articulo.oa?id=75530466001. Ver en web: http://www.revistaestudiosregionales. com/documentos/articulos/pdf-articulo-2420.pdf

Candel, Carlos (2020): “Hacia lo significativo". El Diario de la Educación. https://eldiariodelaeducacion. com/2020/04/03/hacia-lo-significativo/, publicado el 3 de abril de 2020. 
CCOO Enseñanza, Canarias (2020). “Garantizar que el alumnado no pierda el curso es la prioridad”. http:// www2.fe.ccoo.es/ensenanzacanarias/Ensenanza_publica_no_universitaria:Portada:1060096--Garantizar_que_el_alumnado_no_pierda_el_curso_es_la_prioridad.

Diario de Avisos (Tenerife) (2020): “El 31 \% de los estudiantes canarios no tiene ordenador en casa”. https:/ / diariodeavisos.elespanol.com/2020/04/el-31-de-los-estudiantes-canarios-no-tienen-ordenador-en-casa/?fbclid=IwAR07jzXAgfK4BWnZn0yCNdVZKNoMy-ojTWfQsqT1GAdw4kP6644T-AjbVps, publicado el 9 de abril de 2020.

Andrino, Borja; Grasso Daniele y Llaneras Kiko (2019): “¿Escuela de ricos, escuela de pobres? Cómo la concertada y la pública segregan por clase social. El análisis de los centros de España y la renta de sus vecindarios explica cómo la desigualdad afecta al sistema educativo". El País. https://elpais.com/ sociedad/2019/09/30/actualidad/1569832939_154094.html, publicado el 4 de octubre de 2019.

Encinoso, Saray (2020): "Las clases a distancia amenazan con ensanchar la brecha educativa en Canarias". Eldiario.es. https://www.eldiario.es/canariasahora/sociedad/distancia-amenazan-ensanchar-educativa-Canarias_0_1013848801.html, publicado el 7 de abril de 2020.

IE (Instituto Nacional de Evaluación Educativa) - MECD (Ministerio de Educación, Cultura y Deportes) (2011). Evaluación General de Diagnóstico 2010. Educación Secundaria Obligatoria. Segundo Curso. Madrid: MEC y el Instituto de Evaluación (IE). Informe: http://www.mecd.gob.es/dctm/ievaluacion/ informe-egd-2010.pdf?documentId=0901e72b80d5ad3e. Archivo de Datos original recuperado de: http://www.mecd.gob.es/inee/Bases-de-datos.html.

INE (2019). Encuesta sobre Equipamiento y Uso de Tecnologías de Información y Comunicación en hogares. https:/ / www.ine.es/dyngs/INEbase/es/operacion.htm?c=Estadistica_C\&cid=1254736176741\&menu=resultados\&idp=1254735976608\#!tabs-1254736194579.

INE (2019). Encuesta sobre Equipamiento y Uso de Tecnologías de Información y Comunicación en Hogares 2019 (TIC-H'19). Informe Metodológico. https://www.ine.es/metodologia/t25/t25304506619.pdf.

INE (2020). Encuesta Continua de Hogares (ECH) 2019. https://www.ine.es/prensa/ech_2019.pdf.

INE (2020). Encuesta Continua de Hogares (ECH) 2019. Metodología. https://www.ine.es/inebaseDYN/ ech30274/docs/metodologia_ech.pdf.

INE (2018). Encuesta de condiciones de Vida 2018. https://www.ine.es/dyngs/INEbase/es/operacion.ht$\mathrm{m} ? \mathrm{c}=$ Estadistica_C\&cid=1254736176807\&menu=ultiDatos\&idp $=1254735976608$.

INE (2018). Encuesta de condiciones de Vida 2018. Metodología. https://www.ine.es/daco/daco42/condivi/ ecv_metodo.pdf.

Méndez, José Domingo (2020): "Polémica con la consejera de educación de Canarias por llamar 'dinosaurios' a docentes. El Sindicato STEC responde con dureza a la responsable de Educación y le exige "una disculpa pública al profesorado"”. El Día. La opinión de Tenerife. https://www.eldia.es/sociedad/2020/04/07/polemica-consejera-llamar-dinosaurios-docentes/1068338.html?fbclid=IwAR2NJWJ6CrhXVcBCSQOlyi3WZk7zPhHreOzMKkmIJ-pX9MLze7NIOAbiwyI, publicada el 6 de abril de 2020. 
MEyFP (Ministerio de Educación y Formación Profesional) (2020). Las cifras de la educación en España. Estadísticas e Indicadores. Edición 2020. Curso 2017-2018. https:// sede.educacion.gob.es/publiventa/descarga.action?f_codigo_agc $=19668$.

MEyFP (2019). Enseñanzas no Universitarias. Alumnado matriculado. Curso 2017-2018. Resultados detallados. http://www.educacionyfp.gob.es/servicios-al-ciudadano/estadisticas/no-universitaria/alumnado/ matriculado/2017-2018-rd.html.

MEyFP (2019). Sistema Estatal de Indicadores de la Educación. Edición 2019. https:/ /www.educacionyfp.gob. es/inee/dam/jcr:efa745d7-27ec-4814-9e90-11e01957c39d/seie-2019.pdf.

MEyFP (2019). Datosy cifras. Curso escolar 2019-20. https:/ /www.educacionyfp.gob.es/dam/jcr:b998eea276c0-4466-946e-965698e9498d/datosycifras1920esp.pdf.

OECD (2020). A Helping Hand: Education Responding to the Coronavirus Pandemic, by Tracey Burns (Senior Analyst, OECD Directorate for Education and Skills). https://oecdedutoday.com/education-responding-coronavirus-pandemic/.

OECD (2020). Education Disrupted - Education Rebuilt: Some Insights from PIS A on the Availability and Use of Digital tools for Learning, by Andres Schleicher (Director, OECD Directorate for Education and Skills). https://oecdedutoday.com/coronavirus-education-digital-tools-for-learning/.

Orio, Iván (2020): "Si no se vuelve a las aulas, habrá que incorporar contenidos de este curso al inicio del siguiente". El Correo. https://www.elcorreo.com/sociedad/educacion/vuelve-aulas-incorporar-20200328224120-nt.html?ref=https $\% 3 \mathrm{~A} \% 2 \mathrm{~F} \% 2 \mathrm{Fwww} \cdot g o o g l e . c o m \% 2 \mathrm{~F}$, publicada el 28 de marzo de 2020.

Parsons, Talcott (1959): "The School Class as a Social System: Some of its Functions American Society". Harvard Educational Review, 29 (4), 297-318.

Pérez, Carmen; Betancort, Moisés y Cabrera, Leopoldo (2013): "Family Influences in Academic Achievement. A study of the Canary Islands". Revista Internacional de Sociología (RIS), 71 (1), 169-187. DOI: https://doi.org/10.3989/ris.2011.04.11.

Pérez, Carmen; Betancort, Moisés y Cabrera, Leopoldo (2014): "Inversión pedagógica y éxito escolar del alumnado de clase obrera". Revista de la Asociación de Sociología de la Educación, RASE, 7 (2), 410-428. https://ojs.uv.es/index.php/RASE/article/view/8779/8332.

Rogero, Jesús (2020): "Ficción educativa en tiempos de confinamiento". El Diario de la Educación. https:// eldiariodelaeducacion.com/2020/03/25/ficcion-educativa-en-tiempos-de-confinamiento/.

Sanz, Ismael; Sáinz, Jorge y Capilla, Ana (2020): "Efectos de la crisis del coronavirus sobre la educación". Organización de Estados Iberoamericanos para la Educación, la Ciencia y la Cultura (OEI). https://oei.org.br/ arquivos/informe-covid-19d.pdf.

UNESCO (2020). Consecuencias negativas del cierre de las escuelas. https://es.unesco.org/covid19/educationresponse/consecuencias. 
Zafra, Ignacio (2020). "La desesperada búsqueda de los alumnos que se han quedado desconectados del sistema educativo”. El País. https://elpais.com/sociedad/2020-04-12/la-desesperada-busqueda-de-los-alumnos-que-se-han-quedado-desconectados-del-sistema-educativo.html, publicado el 13 abril de 2020 .

\section{Anexo}

Tabla I. Hogares en miles por tipo de hogar y número de habitaciones. Encuesta Continua de Hogares (ECH), 2019

\begin{tabular}{lcccc}
\hline & TOTAL & $\begin{array}{c}\text { MENOS } \\
\text { DE 3 HABITACIONES }\end{array}$ & $\begin{array}{c}\text { ENTRE } 3 \text { Y } 6 \\
\text { HABITACIONES }\end{array}$ & $\begin{array}{c}7 \text { O MÁS } \\
\text { HABITACIONES }\end{array}$ \\
\hline Total (tipo de hogar) & 18580,0 & 280,5 & 15269,2 & 3030,4 \\
\hline Hogar unipersonal & 4771,4 & 183,4 & 4055,4 & 532,6 \\
\hline Hogar monoparental & 1886,8 & 12,7 & 1587,0 & 287,1 \\
\hline Pareja sin hijos que convivan en el hogar & 3920,1 & 61,1 & 3213,1 & 645,9 \\
\hline Pareja con hijos que convivan en el hogar: Total & 6244,2 & 13,9 & 5064,0 & 1166,3 \\
\hline Pareja con hijos que convivan en el hogar: 1 hijo & 2926,8 & 11,7 & 2424,6 & 490,4 \\
\hline Pareja con hijos que convivan en el hogar: 2 hijos & 2765,8 & 2,0 & 2215,8 & 548,0 \\
\hline Pareja con hijos que convivan en el hogar: 3 o más hijos & 551,6 & 0,2 & 423,6 & 127,8 \\
\hline Núcleo familiar con otras personas que no forman núcleo familiar & 803,6 & 1,6 & 600,1 & 202,0 \\
\hline Personas que no forman ningún núcleo familiar entre sí & 548,6 & 6,8 & 464,0 & 77,8 \\
\hline Dos o más núcleos familiares & 405,2 & 0,9 & 285,7 & 118,6 \\
\hline
\end{tabular}

Fuente: elaboración propia con datos del INE (2020), ECH.

Tabla II. Proporción de personas con carencia material por edades en hogares que no pueden permitirse disponer de un ordenador personal en su hogar. Encuesta de Condiciones de Vida (ECV), 2018

\begin{tabular}{|c|c|c|c|c|c|c|c|c|c|c|c|c|c|c|c|}
\hline & \multicolumn{15}{|c|}{ PERSONAS CON CARENCIA MATERIAL POR EDADES (\% DE PERSONAS) } \\
\hline & \multicolumn{15}{|c|}{ NO PUEDE PERMITIRSE DISPONER DE UN ORDENADOR PERSONAL } \\
\hline & 2018 & 2017 & 2016 & 2015 & 2014 & 2013 & 2012 & 2011 & 2010 & 2009 & 2008 & 2007 & 2006 & 2005 & 2004 \\
\hline Total & 5,5 & 5,1 & 7,2 & 7,1 & 7,2 & 6,7 & 6,6 & 5,6 & 7,6 & 8,1 & 8,9 & 9,6 & 11,7 & 12,4 & 14,9 \\
\hline Menores 16 años & 8,0 & 7,0 & 10,4 & 9,7 & 10,4 & 8,7 & 9,7 & 8,2 & 10,8 & 11,8 & 12,8 & 13,3 & 16,9 & 17,2 & 20,5 \\
\hline De 16 a 29 años & 7,4 & 5,3 & 7,7 & 9,3 & 7,0 & 7,3 & 6,6 & 6,5 & 8,4 & 8,9 & 10,0 & 11,4 & 13,4 & 14,5 & 18,0 \\
\hline De 30 a 44 años & 6,3 & 5,3 & 8,4 & 7,4 & 8,3 & 7,1 & 7,4 & 6,4 & 8,1 & 9,5 & 10,7 & 11,0 & 13,0 & 14,2 & 16,6 \\
\hline De 45 a 64 años & 4,6 & 5,1 & 6,5 & 6,6 & 6,6 & 5,9 & 5,6 & 4,4 & 6,1 & 6,0 & 6,4 & 7,2 & 9,3 & 9,8 & 12,1 \\
\hline 65 y más años & 2,7 & 3,0 & 3,4 & 3,2 & 3,8 & 4,7 & 3,9 & 2,9 & 5,0 & 4,5 & 5,0 & 5,3 & 6,3 & 5,8 & 7,4 \\
\hline Menores 18 años & 7,8 & 6,7 & 10,2 & 9,5 & 9,9 & 8,5 & 9,2 & 8,3 & 10,5 & 11,5 & 12,7 & 13,2 & 16,4 & 17,1 & 19,8 \\
\hline De 18 a 64 años & 5,8 & 5,3 & 7,4 & 7,5 & 7,4 & 6,6 & 6,6 & 5,6 & 7,4 & 8,1 & 8,9 & 9,7 & 11,8 & 12,7 & 15,5 \\
\hline
\end{tabular}

Fuente: elaboración propia con datos del INE (2018), ECV. https://www.ine.es/jaxiT3/Datos.htm?t=9967\#!tabs-tabla. 
Tabla III. Proporción de personas con carencia material por tipología de hogares que no pueden permitirse disponer de un ordenador personal en su hogar. Encuesta de Condiciones de Vida (ECV), 2018

\begin{tabular}{|c|c|c|c|c|c|c|c|c|c|c|c|c|c|c|c|}
\hline \multirow[b]{3}{*}{ HOGARES/AÑOS } & \multicolumn{15}{|c|}{ PERSONAS CON CARENCIA MATERIAL POR TIPO DE HOGAR (\% DE PERSONAS) } \\
\hline & \multicolumn{15}{|c|}{ NO PUEDE PERMITIRSE DISPONER DE UN ORDENADOR PERSONAL } \\
\hline & 2018 & 2017 & 2016 & 2015 & 2014 & 2013 & 2012 & 2011 & 2010 & 2009 & 2008 & 2007 & 2006 & 2005 & 2004 \\
\hline Total & 5,5 & 5,1 & 7,2 & 7,1 & 7,2 & 6,7 & 6,6 & 5,6 & 7,6 & 8,1 & 8,9 & 9,6 & 11,7 & 12,4 & 14,9 \\
\hline De 1 persona & 5,1 & 4,9 & 5,8 & 6,4 & 7,9 & 6,4 & 6,2 & 5,5 & 8,6 & 7,2 & 6,6 & 9,6 & 8,0 & 9,1 & 9,9 \\
\hline 2 adultos sin niños & 3,5 & 4,6 & 4,8 & 4,8 & 5,2 & 5,5 & 4,7 & 3,5 & 5,3 & 5,7 & 6,3 & 7,0 & 8,7 & 8,5 & 10,5 \\
\hline Otros sin niños & 4,7 & 4,5 & 5,5 & 6,3 & 6,6 & 6,2 & 6,0 & 5,0 & 6,6 & 6,9 & 7,4 & 7,9 & 11,3 & 11,0 & 13,8 \\
\hline 1 adulto + 1 niño 0 + & 11,5 & 8,0 & 8,3 & 13,3 & 12,0 & 8,7 & 6,5 & 14,0 & 11,7 & 14,8 & 13,7 & 17,4 & 24,5 & 28,0 & 23,9 \\
\hline 2 adultos+ 1 niño $0+$ & 5,6 & 5,1 & 8,2 & 7,0 & 7,7 & 6,0 & 6,8 & 6,0 & 7,9 & 9,0 & 9,5 & 9,3 & 12,3 & 13,9 & 16,1 \\
\hline Otros hogares con niños & 9,5 & 6,5 & 12,2 & 12,0 & 8,7 & 10,9 & 10,3 & 7,4 & 10,3 & 10,6 & 13,6 & 14,6 & 15,2 & 15,4 & 22,5 \\
\hline No consta & 13,1 & 0,0 & 0,0 & 15,4 & 0,0 & 0,0 & 0,0 & 11,8 & 0,0 & $\ldots$ & 0,0 & 6,4 & 11,2 & 11,8 & 11,2 \\
\hline
\end{tabular}

Fuente: elaboración propia con datos del INE (2018), ECV.

https://www.ine.es/jaxiT3/Datos.htm?t=9971\#!tabs-tabla.

Niño dependiente menor de 18 años y personas inactivas de 18 a 24 años.

Tabla IV. Número total de viviendas y tipo de equipamiento (\%), por Comunidad Autónoma. Año 2019

\begin{tabular}{|c|c|c|c|c|c|c|}
\hline & TOTAL VIVIENDAS & $\begin{array}{l}\text { VIVIENDAS CON } \\
\text { ALGÚN TIPO DE } \\
\text { ORDENADOR }\end{array}$ & $\begin{array}{l}\text { VIVIENDAS QUE } \\
\text { DISPONEN DE } \\
\text { ACCESO } \\
\text { A INTERNET }\end{array}$ & $\begin{array}{l}\text { VIVIENDAS CON } \\
\text { CONEXIÓN DE } \\
\text { BANDA ANCHA } \\
\text { (ADSL, RED DE } \\
\text { CABLE, ETC.) }\end{array}$ & $\begin{array}{l}\text { VIVIENDAS CON } \\
\text { TELÉFONO FIJO }\end{array}$ & $\begin{array}{l}\text { VIVIENDAS CON } \\
\text { TELÉFONO MÓVIL }\end{array}$ \\
\hline Total & 16451384 & 80,9 & 91,4 & 91,2 & 74,9 & 98,5 \\
\hline Andalucía & 2874364 & 76,8 & 89,7 & 89,2 & 68,2 & 98,1 \\
\hline Aragón & 471109 & 84,9 & 92,1 & 91,6 & 81,8 & 98,7 \\
\hline Asturias, Principado de & 394125 & 79,5 & 91,1 & 90,8 & 72,9 & 98,1 \\
\hline Balears, Illes & 414736 & 84,5 & 93,1 & 93,0 & 82,2 & 99,2 \\
\hline Canarias, Islas & 781388 & 80,3 & 91,1 & 90,4 & 79,2 & 97,9 \\
\hline Cantabria & 209549 & 80,7 & 90,8 & 90,8 & 78,2 & 97,2 \\
\hline Castilla y León & 846519 & 78,0 & 89,0 & 88,6 & 76,5 & 98,0 \\
\hline Castilla-La Mancha & 690719 & 74,2 & 86,8 & 86,7 & 66,7 & 97,2 \\
\hline Cataluña & 2645878 & 84,9 & 94,0 & 93,9 & 79,8 & 98,4 \\
\hline Comunidad Valenciana & 1782215 & 80,0 & 90,6 & 90,5 & 64,1 & 98,8 \\
\hline Extremadura & 373468 & 74,7 & 89,3 & 89,2 & 64,9 & 98,5 \\
\hline Galicia & 967264 & 73,3 & 88,8 & 88,1 & 72,3 & 98,2 \\
\hline Madrid, Comunidad de & 2336249 & 87,8 & 94,5 & 94,5 & 87,4 & 99,1 \\
\hline Murcia, Región de & 488426 & 78,1 & 91,3 & 91,0 & 52,5 & 98,9 \\
\hline Navarra, Comunidad Foral de & 221808 & 87,5 & 95,0 & 94,5 & 81,6 & 99,6 \\
\hline País Vasco & 791680 & 83,2 & 91,5 & 91,4 & 82,7 & 98,9 \\
\hline Rioja, La & 113327 & 78,4 & 90,6 & 90,0 & 75,1 & 97,5 \\
\hline Ceuta, Ciudad Autónoma & 18607 & 86,3 & 91,7 & 91,7 & 85,7 & 98,0 \\
\hline Melilla, Ciudad Autónoma & 29954 & 82,2 & 91,2 & 91,2 & 73,3 & 100,0 \\
\hline
\end{tabular}

Fuente: elaboración propia con datos del INE (2019).

Encuesta sobre Equipamiento y Uso de Tecnologías de Información y Comunicación en Hogares (TIC-H’19). 
Tabla V. Número total de viviendas y proporción de dispositivos (\%) en el hogar, por Comunidades Autónomas

\begin{tabular}{|c|c|c|c|c|}
\hline & TOTAL VIVIENDAS & $\begin{array}{c}\text { ORDENADOR } \\
\text { (CUALQUIER TIPO) }\end{array}$ & TELÉFONO FIJO & TABLETA \\
\hline Total nacional & 16451384 & 80,9 & 98,5 & 56,8 \\
\hline Andalucía & 2874364 & 76,8 & 98,1 & 54,6 \\
\hline Aragón & 471109 & 84,9 & 98,7 & 54,7 \\
\hline Asturias, Principado de & 394125 & 79,5 & 98,1 & 54,3 \\
\hline Balears, Illes & 414736 & 84,5 & 99,2 & 59,8 \\
\hline Canarias, Islas & 781388 & 80,3 & 97,9 & 57,4 \\
\hline Cantabria & 209549 & 80,7 & 97,2 & 55,8 \\
\hline Castilla y León & 846519 & 78,0 & 98,0 & 54,7 \\
\hline Castilla-La Mancha & 690719 & 74,2 & 97,2 & 50,3 \\
\hline Cataluña & 2645878 & 84,9 & 98,4 & 59,8 \\
\hline Comunidad Valenciana & 1782215 & 80,0 & 98,8 & 54,3 \\
\hline Extremadura & 373468 & 74,7 & 98,5 & 52,8 \\
\hline Galicia & 967264 & 73,3 & 98,2 & 47,0 \\
\hline Madrid, Comunidad de & 2336249 & 87,8 & 99,1 & 65,3 \\
\hline Murcia, Región de & 488426 & 78,1 & 98,9 & 54,6 \\
\hline Navarra, Comunidad Foral de & 221808 & 87,5 & 99,6 & 60,6 \\
\hline País Vasco & 791680 & 83,2 & 98,9 & 57,5 \\
\hline Rioja, La & 113327 & 78,4 & 97,5 & 53,2 \\
\hline Ceuta, Ciudad Autónoma & 18607 & 86,3 & 98,0 & 71,7 \\
\hline Melilla, Ciudad Autónoma & 29954 & 82,2 & 100,0 & 56,1 \\
\hline
\end{tabular}

Fuente: elaboración propia con datos del INE (2019).

Encuesta sobre Equipamiento y Uso de Tecnologías de Información y Comunicación en Hogares (TIC-H’19).

Tabla VI. Número total de personas de 16 a 74 años y uso de internet (\%), por Comunidades Autónomas

\begin{tabular}{|c|c|c|c|c|c|c|c|}
\hline & TOTAL & $\begin{array}{l}\text { HAN UTILIZADO } \\
\text { INTERNET } \\
\text { ALGUNA VEZ }\end{array}$ & $\begin{array}{l}\text { HAN UTILIZADO } \\
\text { INTERNET EN } \\
\text { LOS ÚLTIMOS } 12 \\
\text { MESES }\end{array}$ & $\begin{array}{l}\text { HAN UTILIZADO } \\
\text { INTERNET EN LOS } \\
\text { ÚLTIMOS } 3 \text { MESES }\end{array}$ & $\begin{array}{l}\text { HAN UTILIZADO } \\
\text { INTERNET EN EL } \\
\text { ÚLTIMO MES }\end{array}$ & $\begin{array}{l}\text { HAN UTILIZADO } \\
\text { INTERNET } \\
\text { SEMANALMENTE } \\
\text { (AL MENOS } \\
\text { UNA VEZ } \\
\text { A LA SEMANA) }\end{array}$ & $\begin{array}{l}\text { HAN UTILIZADO } \\
\text { INTERNET } \\
\text { DIARIAMENTE } \\
\text { (AL MENOS UNA } \\
\text { VEZ AL DÍA) }\end{array}$ \\
\hline Total nacional & 34910798 & 91,6 & 91,0 & 90,7 & 90,2 & 87,7 & 77,6 \\
\hline Andalucía & 6295225 & 90,7 & 89,8 & 89,4 & 88,9 & 86,4 & 77,4 \\
\hline Aragón & 964226 & 92,6 & 92,1 & 91,8 & 91,3 & 88,6 & 78,6 \\
\hline Asturias, Ppdo de & 766377 & 90,7 & 89,7 & 89,2 & 88,8 & 85,1 & 75,0 \\
\hline Balears, Illes & 915377 & 94,6 & 94,4 & 94,1 & 94,1 & 90,2 & 78,3 \\
\hline Canarias, Islas & 1730386 & 90,9 & 90,0 & 89,7 & 89,1 & 86,8 & 75,7 \\
\hline Cantabria & 434582 & 90,3 & 89,5 & 89,1 & 89,0 & 85,5 & 74,9 \\
\hline Castilla y León & 1747285 & 89,1 & 88,8 & 88,6 & 87,9 & 84,8 & 73,1 \\
\hline Castilla-La Mancha & 1495152 & 87,5 & 87,4 & 87,2 & 86,6 & 83,2 & 72,8 \\
\hline Cataluña & 5599000 & 94,2 & 93,8 & 93,7 & 93,1 & 91,1 & 81,0 \\
\hline Com Valenciana & 3711496 & 90,4 & 89,8 & 89,7 & 89,2 & 87,5 & 75,5 \\
\hline Extremadura & 788139 & 89,0 & 88,9 & 88,6 & 88,2 & 84,8 & 75,1 \\
\hline Galicia & 1988284 & 85,7 & 84,8 & 84,0 & 83,4 & 79,7 & 67,1 \\
\hline Madrid, Com de & 4946550 & 95,2 & 94,4 & 94,1 & 93,6 & 91,7 & 83,1 \\
\hline Murcia, Región de & 1103213 & 90,7 & 90,0 & 89,8 & 89,7 & 88,1 & 81,5 \\
\hline
\end{tabular}


HAN UTILIZADO INTERNET

SEMANALMENTE

(AL MENOS

UNA VEZ

A LA SEMANA)

HAN UTILIZADO

INTERNET

DIARIAMENTE

(AL MENOS UNA

VEZ AL DÍA)

\begin{tabular}{|c|c|c|c|c|c|c|c|}
\hline TotaL nacional & 34910798 & 91,6 & 91,0 & 90,7 & 90,2 & 87,7 & 77,6 \\
\hline Navarra, Com F & 476723 & 95,6 & 95,1 & 95,0 & 94,8 & 91,4 & 80,2 \\
\hline País Vasco & 1600890 & 92,2 & 91,7 & 91,5 & 91,3 & 88,1 & 77,8 \\
\hline Rioja, La & 229890 & 90,6 & 89,9 & 89,6 & 88,2 & 85,1 & 75,0 \\
\hline Ceuta, Cd Auto & 59124 & 98,1 & 98,1 & 94,9 & 94,9 & 87,5 & 81,9 \\
\hline Melilla, Cd Auto & 58879 & 87,6 & 87,6 & 87,6 & 87,6 & 85,3 & 75,1 \\
\hline
\end{tabular}

Fuente: INE (2019). Encuesta sobre Equipamiento y Uso de Tecnologías de Información y Comunicación en Hogares (TIC-H’19).

Tabla VII. Total de niños de 10 a 15 años usuarios de ordenador (\%) y de internet (\%) en los últimos tres meses, y que disponen de móvil (\%), por Comunidad Autónoma. Año 2019

\begin{tabular}{|c|c|c|c|c|}
\hline & TOTAL & $\begin{array}{c}\text { USUARIOS } \\
\text { DE ORDENADOR \% }\end{array}$ & $\begin{array}{c}\text { USUARIOS } \\
\text { DE INTERNET \% }\end{array}$ & $\begin{array}{l}\text { TIENEN } \\
\text { MÓVIL \% }\end{array}$ \\
\hline Total & 2992532 & 89,7 & 92,9 & 66,0 \\
\hline Andalucía & 585804 & 86,2 & 90,7 & 64,0 \\
\hline Aragón & 79922 & 94,1 & 95,1 & 72,1 \\
\hline Asturias, Principado de & 49085 & 97,4 & 97,4 & 65,1 \\
\hline Balears, Illes & 74412 & 94,1 & 88,6 & 67,1 \\
\hline Canarias, Islas & 135184 & 89,9 & 89,0 & 66,0 \\
\hline Cantabria & 34229 & 96,3 & 91,6 & 63,1 \\
\hline Castilla y León & 125716 & 93,1 & 96,6 & 68,0 \\
\hline Castilla-La Mancha & 133738 & 90,2 & 92,5 & 71,5 \\
\hline Cataluña & 503485 & 92,8 & 95,4 & 66,7 \\
\hline Comunidad Valenciana & 325509 & 82,8 & 91,6 & 64,2 \\
\hline Extremadura & 63886 & 91,6 & 92,6 & 77,6 \\
\hline Galicia & 137970 & 89,9 & 96,2 & 57,0 \\
\hline Madrid, Comunidad de & 427908 & 88,4 & 91,5 & 65,6 \\
\hline Murcia, Región de & 108569 & 90,7 & 95,7 & 65,0 \\
\hline Navarra, Comunidad Foral de & 42718 & 99,2 & 92,0 & 64,7 \\
\hline País Vasco & 130107 & 97,0 & 95,8 & 73,1 \\
\hline Rioja, La & 19656 & 93,2 & 92,7 & 70,9 \\
\hline Ceuta, Ciudad Autónoma & 7343 & 86,0 & 88,4 & 46,5 \\
\hline Melilla, Ciudad Autónoma & 7291 & 79,6 & 94,7 & 69,7 \\
\hline
\end{tabular}

Fuente: INE (2019). Encuesta sobre Equipamiento y Uso de Tecnologías de Información y Comunicación en Hogares (TIC-H’19). 


\section{Gráfico 1. Porcentaje de alumnado matriculado por titularidad del centro, niveles educativos y Comunidades Autónomas. Curso 2016-17}
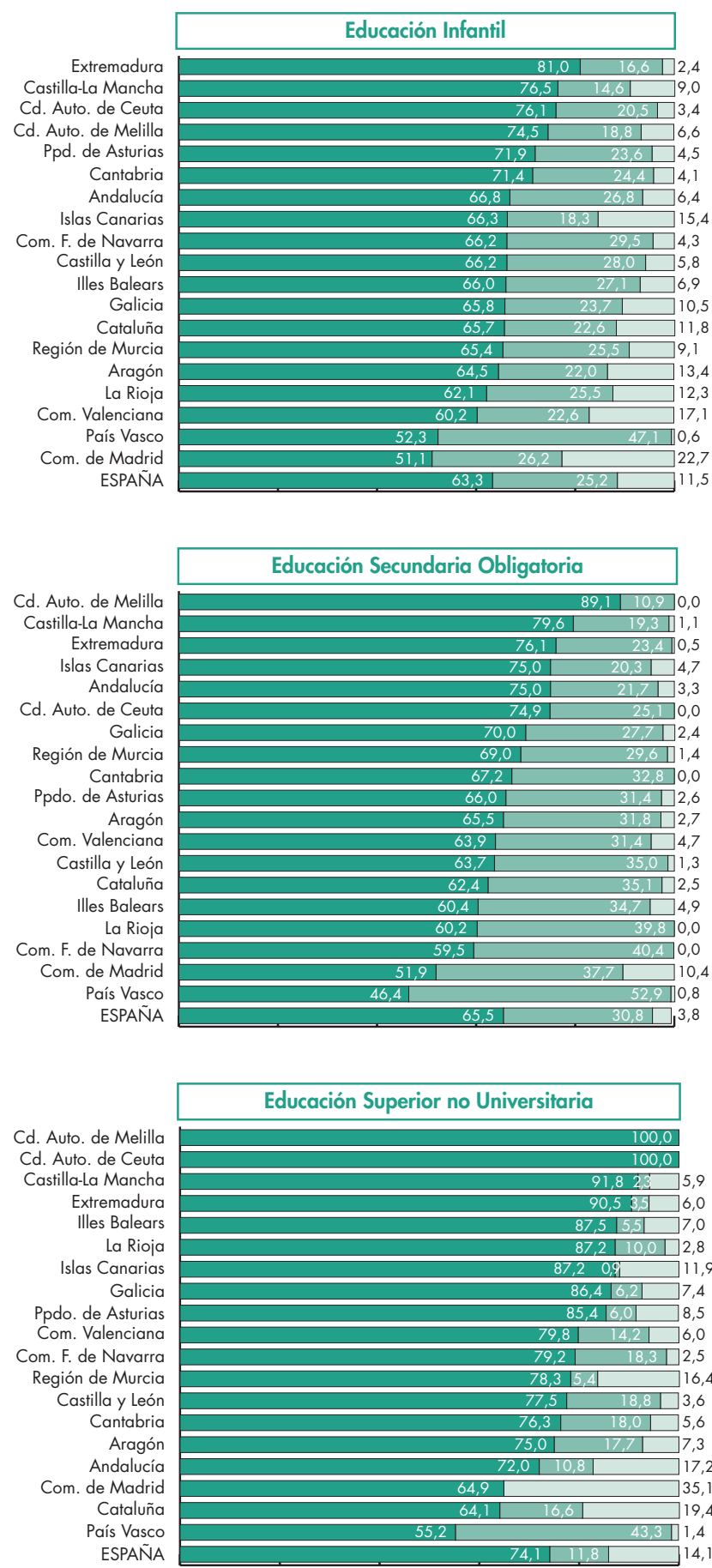
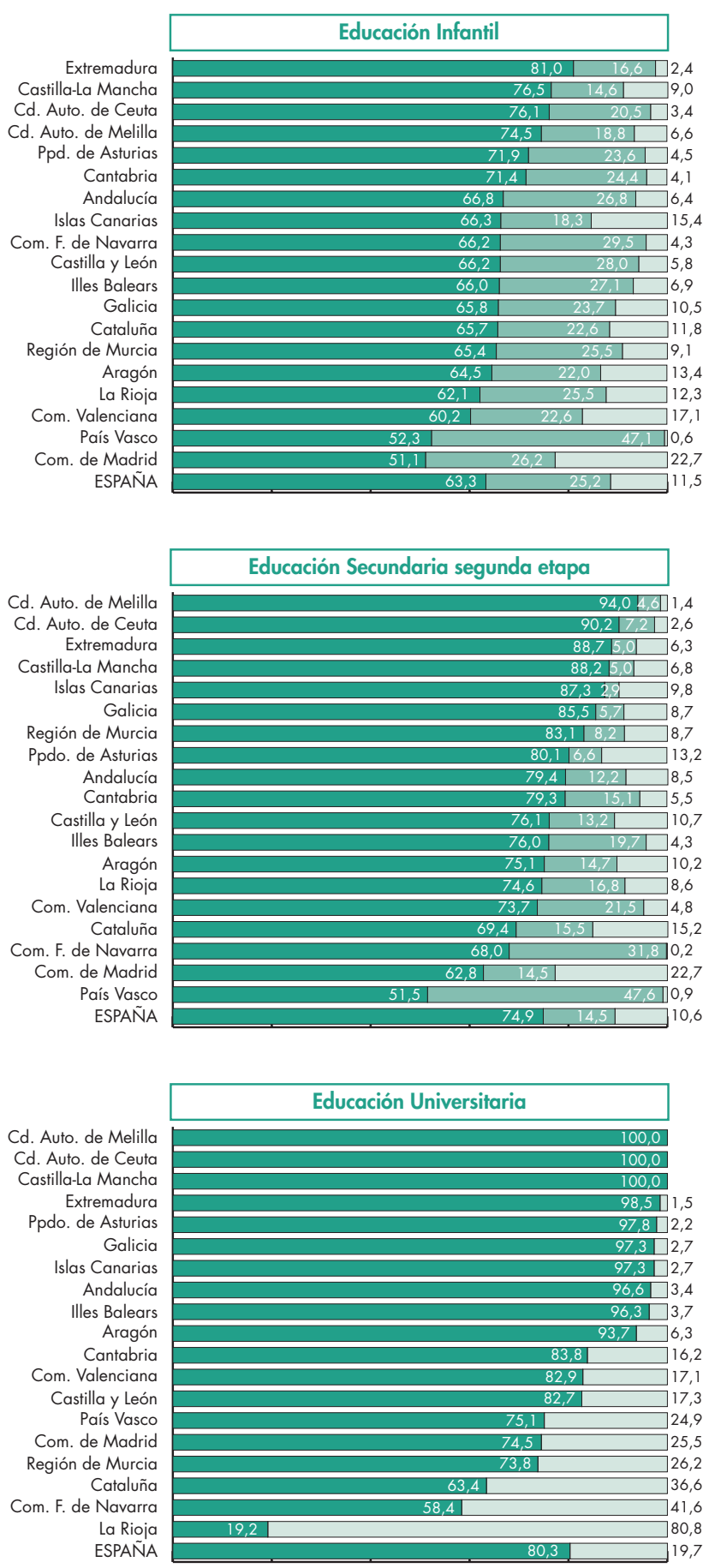

Centros privados no concertados

NOTA: las CC.AA. están en orden decreciente según el porcentaje de los alumnos escolarizados en centros públicos.

Fuente: MEyFP (2019: 19; SIE Indicador E1.2, Gráfico 1, gráfico E1.2). 


\section{Nota biográfica}

Leopoldo Cabrera es profesor de Sociología de la Educación y de Tratamiento y Análisis de Datos, Departamento de Sociología y Antropología de la Universidad de La Laguna. CEDESOG (Centro de Estudios de Desigualdad Social y Gobernanza). ISTUR (Instituto de Investigación Social y Turismo). Presidente del Comité de Investigación de Sociología de la Educación de la Federación Española de Sociología.

Orcid: https://orcid.org/0000-0003-2337-7436. 